\title{
LAS PLACAS DE CINTURÓN «MÚLTIPLE» HISPANOVISIGODAS. A PROPÓSITO DE LA HALLADA EN SAUCEDO, TALAVERA LA NUEVA (TOLEDO)
}

POR

\author{
BARBARA SASSE \\ Estipendaria de la Deutsche Forschungsgemeinschaft. \\ RAQUEL CASTELO RUANO \\ Universidad Autónoma de Madrid. \\ MARÍA LUISA RAMOS SÁINZ \\ Universidad de Cantabria.
}

\section{RESUMEN}

Las placas de cinturones múltiples, son un conjunto de piezas conocidas en Europa oriental y central (incluida Italia), en el Imperio bizantino, en Persia, en Asia central y China. En Europa están datadas desde finales del siglo vi hasta principios del siglo VIII (Werner, 1974). En Asia se documentaron hasta el siglo pasado. En la Península Ibérica, piezas semejantes eran prácticamente desconocidas. El hallazgo de una placa "vertical» de este tipo de cinturón nos permite valorar los problemas en un nuevo contexto.

\section{SUMMARY}

Multipartite strap sets are found in Eastern and Central Europe (including Italy), in the Byzantine empire, in Persia, Central Asia and China. In Europe they are dated from the end of the 6th to the beginning of the 8th century. In Asia, they were in use still in the last century, but in the Iberian Peninsula they were practically unknown until now. The find of a "vertical metal fitting" in the province of Toledo gives us reason to consider the problems of these belts in an other context than previously.

\section{INTRODUCCIÓN}

La pieza' que nos ocupa fue descubierta en la villa romana de Saucedo, situada en el término municipal de Talavera de la Reina, junto a la población de Talavera la Nueva, durante el transcurso de la primera campaña de excavaciones efectuada en 1982

\footnotetext{
' Depositada en el Museo de Santa Cruz de Toledo. $N^{\circ}$ de Inventario 270667.
}

por el Departamento de Prehistoria y Arqueología de la Universidad Autónoma de Madrid y bajo la dirección del profesor M. Bendala Galán.

Como consecuencia de los trabajos arqueológicos se detectaron en la villa dos fases constructivas. La primera datada en el Alto-Imperio, concretamente en la segunda mitad del siglo । d.C. y la segunda fechada desde época Bajo-Imperial del siglo Iv d.C., hasta época visigoda avanzada del siglo vII d.C. (Ramos y Durán, 1985, 237). La primera fase, en la que apenas se halló material quedó datada por el hallazgo de algunos fragmentos de Terra Sigillata Gálica decorada (Dragendorff 29) y lisa (Dragendorff 24-25) fechados en la segunda mitad del siglo I d.C. A esta primera etapa corresponden los restos de una estructura con ambiente central circular y suelo de opus signinum con una moldura en cuarto de bocel característica de un espacio de carácter hidráulico. Probablemente se trate de un pequeño estanque rodeado por un muro concéntrico, en el que se abren cuatro pequeños ambientes cuadrangulares opuestos entre sí, formando una planta cruciforme. La estructura más parecida a la de Saucedo es la que se encuentra en la villa portuguesa de Mexil Moreira Grande (Abicada, Faro), de la que desafortunadamente tampoco conocemos su funcionalidad (Gorges, 1979, pl. LVIII).

La segunda fase constructiva, separada de la anterior por un hiatus temporal de varios siglos, fue bien fechada por el hallazgo de una serie de monedas datadas en los siglos iv y $\mathrm{v}$, etapa que se prolon- 
ga hasta el siglo viII d.C. Las monedas documentadas en los siglos iv y $\vee$ d.C. son: aes de Graciano (367-383), Honorio (393-423), Teodosio (379-395) y Valentiniano II (375-392); entre las monedas del siglo vil destaca un triens de Witiza (698-710) (Ramos y Durán, 1985, 238-239).

No existió una continuidad entre las dos fases constructivas, pues se advierte una ruptura con respecto a la planificación anterior. $\mathrm{Al}$ ambiente circular de la primera fase se le superpuso una habitación rectangular, dividida en dos compartimentos, que por el material hallado, parece corresponder a lugares relacionados con dependencias dedicadas al almacenamiento de enseres. Estos ambientes se verán afectados por un incendio que los destruirá violentamente. Es precisamente en este lugar, bajo la capa de cenizas y derrumbe, donde apareció la pieza que ahora estudiamos.

Correspondiente a la segunda fase, se hallaron al oeste de las dependencias descritas, una serie de habitaciones con ricos pavimentos musivos próximas a un área termal. Estas dependencias de mayor lujo que las descritas anteriormente, debieron formar parte de la vivienda del dominus y su familia. Posteriormente en época visigoda, esta zona residencial fue reutilizada y transformada en basílica, a la que se añade una piscina bautismal de planta cruciforme (Ramos Sáinz y Castelo Ruano, 1992, 115137 y Ramos Sáinz, 1992, 105-110).

\section{LA PLACA DE CINTURÓN}

\section{Descripción}

La pieza es una placa vertical ligeramente curvada realizada en hierro con una decoración damasquinada en plata y latón. Esta presenta en la parte superior un remate semicircular y en la parte inferior dos apéndices circulares. La pieza tiene en su reverso tres remaches, dos en la parte superior y uno debajo del apéndice extremo. Las dimensiones son: longitud: $106 \mathrm{~mm}$, ancho: $21 \mathrm{~mm}$, grosor: $5 \mathrm{~mm}$, el diámetro de los apéndices: $20 \mathrm{~mm}$. La superficie, especialmente en la mitad de la parte superior de la pieza, se encuentra en mal estado de conservación debido a la corrosión. Por esta causa las láminas del damasquinado faltan casi totalmente en esta zona. Está decorada en su totalidad con la técnica de damasquinado, presenta láminas de plata en disposición vertical, horizontal y radial todas ellas enmarcadas por filamentos también en plata. La placa está circundada por láminas paralelas realizadas en plata y latón.
En la parte superior de la pieza se documenta una lámina central en disposición vertical. $\mathrm{A}$ ambos lados se colocaron láminas finas horizontales y paralelas. En la mitad de la parte superior (prácticamente destruida) y en concreto en el lateral izquierdo se aprecian dos pequeñas láminas verticales un poco más anchas que las dispuestas en horizontal. En los dos extremos de la parte superior existen láminas verticales. Los dos apéndices circulares separados por una lámina horizontal presentan tres circulos concéntricos. El central, de latón, presenta un cabujón con vidrio de color granate. Los dos circulos restantes se rellenan con láminas de plata en disposición radial. El círculo interior presenta cinco puntos irregulares situados en el extremo final de los radios. En el interior del círculo más exterior, y cada tres filamentos, se coloca en la parte superior un punto. La decoración de los dos apéndices no es completamente exacta (fig. 1, a y b).

\section{Análisis metalográfico 2}

La pieza está formada por un cuerpo macizo de hierro forjado, cuya superficie vista exhibe una decoración damasquinada con diseños geométricos, alternando tonos metálicos de color plateado y dorado.

El análisis cualitativo espectrométrico por fluorescencia de rayos X (EDX) del metal del damasquinado indica que las laminillas plateadas son, efectivamente de plata, mientras que las de color dorado son de latón (aleación cobre y cinc). No se ha podido determinar la composición cualitativa de estos metales debido a la configuración del analizador, que mezcla las señales del hierro del soporte y de las laminillas de plata y latón. En estas condiciones, una parte de la señal correspondiente al cobre puede corresponder a impurezas de este metal en la liga de la plata (cosa muy frecuente en época medieval) y no sólo al latón. En cualquier caso, los tipos básicos de aleación presentes quedan suficientemente garantizados.

El estudio bajo la óptica del microscopio metalográfico detecta la técnica de damasquinado empleada para fijar las láminas decorativas al soporte. El avanzado estado de corrosión del hierro no permite distinguir las posibles camas que sirvieron para fijar la lámina al soporte. En todo caso no se trata de un damasquinado con hilo martilleado hasta laminarlo sino de una aplicación de láminas que luego fueron recortadas con ayuda de punzones o cincelillos de

\footnotetext{
${ }^{2}$ Queremos agradecer al Dr. Salvador Rovira los análisis metalográficos realizados a la pieza procedente de Saucedo (Toledo).
} 

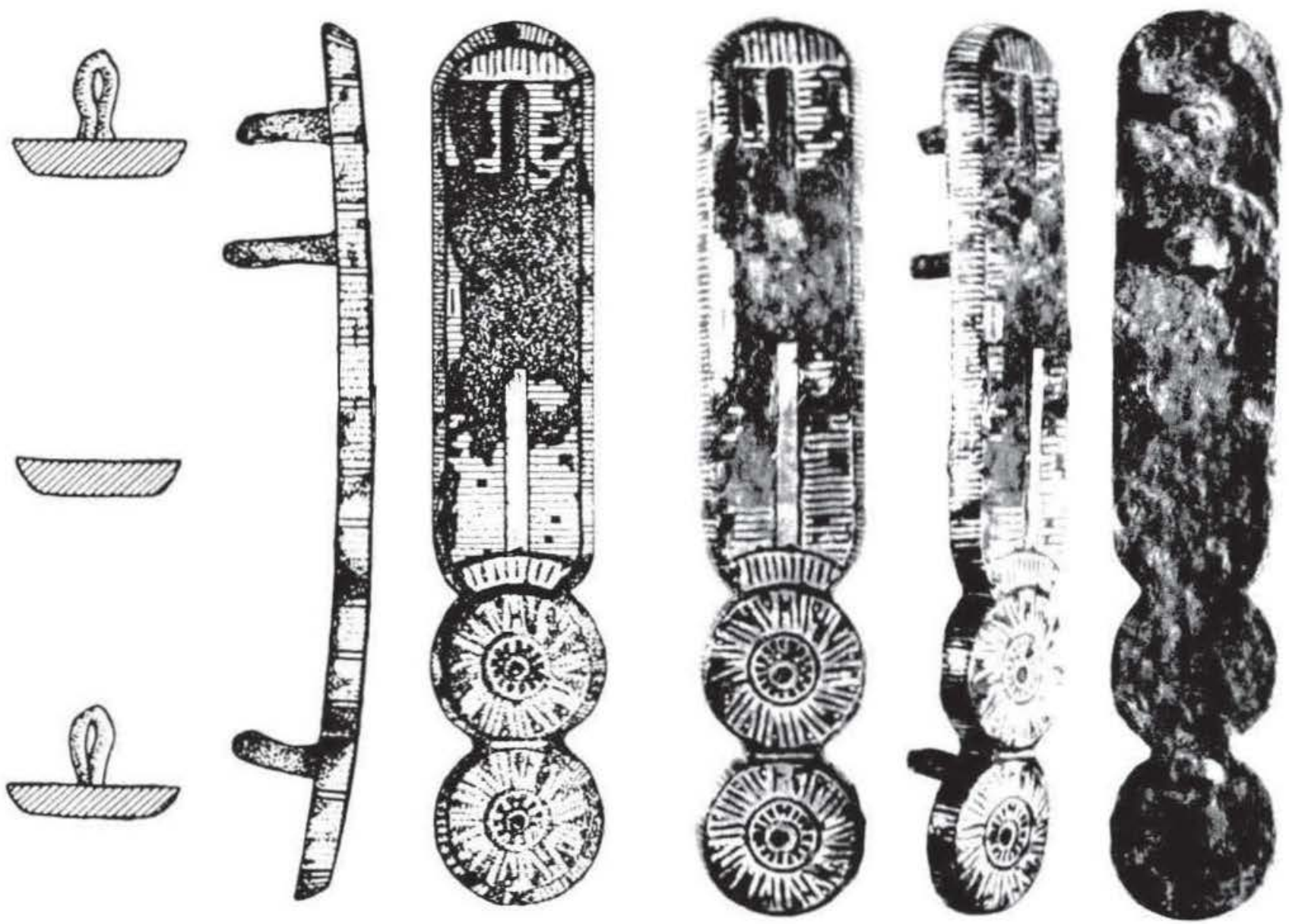

(l

b

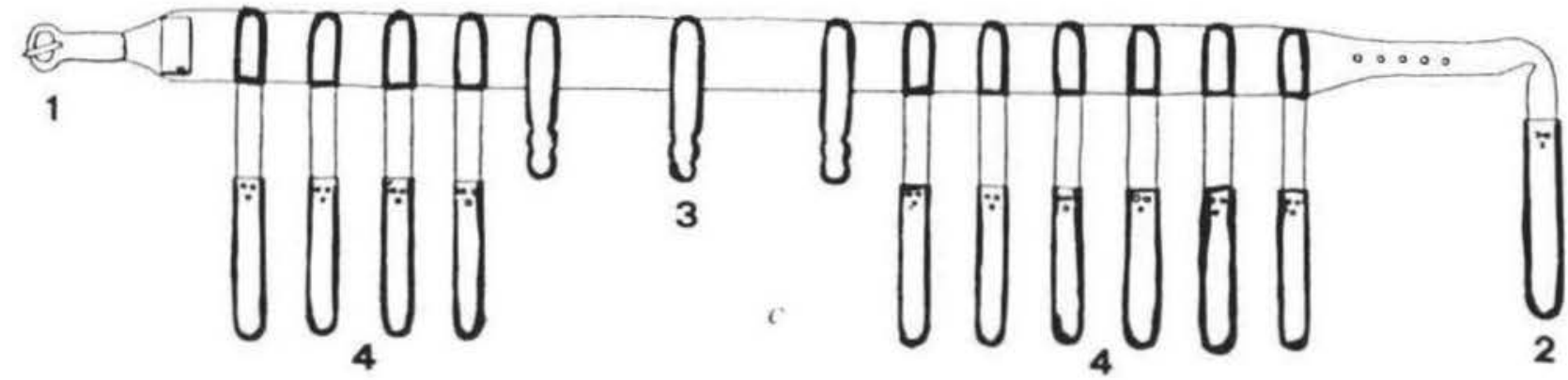

Figura 1, $a$ y b Dibujo y fotografias de la placa vertical de un cinturón múltiple hallado en la villa romana de Saucedo (Talavera La Nueva. Talavera de la Reina. Toledo). Escala 1: I. Foto: Instituto Arqueológico Alemán J. Patterson; c lisquema de un cinturón múltiple. Piezas que lo componen: I. hebilla: 2, lengüeta final o principal: 3. placas verticales; 4 , placas colgantes, segun Christlein.

platero, cuyos bocados son perfectamente perceptibles en los perfiles trabajados del dibujo y en las yuxtaposiciones de plata/latón. Aunque la conservación de la decoración es bastante buena en zonas, el latón se encuentra más afectado por la corrosión, como corresponde a metales de distinta nobleza.
El rayado uniforme que se aprecia en la superficie metálica parece consecuencia del tratamiento mecánico con abrasivos aplicados para su limpieza y restauración.

Los cabujones contienen fragmentos de vidrio o pasta vitrea. 
Análisis de la técnica decorativa. Paralelos peninsulares $y$ extrapeninsulares

La pieza es única por el momento en la peninsula ibérica, aunque existen algunos hallazgos con decoración damasquinada muy semejante a la que presenta la placa de Saucedo. Entre éstos podemos mencionar los frenos de caballo que se conservan en las colecciones de la Armeria Real y del Instituto Valencia de Don Juan (Palol, 1957, 298-302, láminas III y IV), de gran interés para el estudio que aquí presentamos, aunque se trata de hallazgos sin contexto, y cuya decoración se caracteriza por tener laminillas dispuestas en horizontal, vertical y radial. También habria que citar dos placas circulares con estribos pertenecientes a un arnés de caballo; proceden de un hallazgo casual realizado en Solosancho (Avila), conservadas en la colección Gómez Moreno del Museo Arqueológico Nacional de Madrid (Palol, 1957, 302 y Zeiss, 1934, 67). Según Posac en esta misma colección se conservaban «diversas piedras de origen visigodo" procedentes también de Solosancho (Posac, 1952, 63).

Las placas circulares con estribos, realizadas en hierro, están decoradas en el anverso probablemente con damasquinado realizado con hilos de plata y con la técnica conocida por Salin como placage o damasquinado en áreas en el motivo central (Salin, 1951, 33-44, fig. 16 y 1957, 163-166). Los motivos decorativos son: circulos concéntricos que enmarcan otros entre los que destacan: entrelazados punteados, zig-zag , celdillas y cuadrículas (Zeiss, 1934, lám. 27, 1-3).

Todo el conjunto de hallazgos remite al mundo merovingio, donde existen piezas muy semejantes en tumbas de guerreros con ajuares muy ricos. Los motivos de los arneses antes descritos se repiten en las placas de cinturones del tipo Bülach identificados por Werner (1953, 31, láms. XXVIII y XXIX). Estos elementos de cinturón están bien fechados en la primera fase de la etapa IV de Böhner, datada en la primera mitad del siglo vil d.C. (Böhner, 1958 y Ament, 1976).

$\mathrm{El}$ estudio de las necrópolis del período merovingio permite conocer que también el tipo de placa hallado en Saucedo, formaba parte de los ajuares funerarios. En Europa central y concretamente en el cementerio de München-Pasing (Baviera), sepultura número 2 , encontramos tres placas verticales de un cinturón múltiple casi idénticas a la que aqui presentamos (Fig. 2a). Otra placa vertical de las mismas características que las citadas anteriormente fue encontrada junto a las piezas de un cinturón múltiple en la necrópolis, hoy destruida, de Peitiug Ldkr.
Schongau, Baviera (Stein, 1967, 240, 244, Taf. 79.1-3 y 80.2). Estas cuatro piezas permiten reconstruir la decoración de la placa de Saucedo. En su descripción indicamos la existencia en la parte superior, y en concreto en el lateral izquierdo, de dos pequeñas láminas verticales mas anchas que las dispuestas en horizontal: se trata del extremo final del travesaño de una cruz. El brazo vertical lo forma la lámina central ya aludida en la descripción. Las placas de München-Pasing son casi idénticas aunque se pueden constatar algunas diferencias notables: en los ejemplos bávaros la lámina central está formada por dos láminas verticales paralelas decoradas con motivos circulares estampillados y en el ejemplar de Saucedo por una sola lámina sin decoración. Existen también pequeñas diferencias en la decoración de los dos apéndices, los ejemplos procedentes de Baviera presentan un solo circulo de mayor anchura con hilos en disposición radial; entre los radios no se advierte la presencia de puntos que sí se constatan en la placa de Saucedo.

\section{EL CINTURÓN MÚLTIPLE}

\section{Historia de la investigación}

El fenómeno de los cinturones múltiples en España es prácticamente desconocido por lo que nos parece necesario resumir los estudios realizados por diversos investigadores alemanes, húngaros, franceses e italianos. Estos estudiosos se preocuparon de muy diversos temas que hemos agrupado de la siguiente manera: $a$ ) Definición, distribución y tipología; $b$ ) Intentos de reconstrucción y funcionalidad; $c$ ) Estatus social de los poseedores; $d$ ) Cronología; y e) Tecnologia.

a) Definición, distribución y tipología. El primer autor que describió las placas de cinturones múltiples fue Nils Åberg en 1923, aunque no determinó cuál sería su funcionalidad. Los ejemplares procedian de las necrópolis del Norte de Italia (Nocera Umbra, Castel Trosino, Chiusi y Arcisa). Determinó la existencia de tres tipos distintos: bizantinos realizados en plata, oro o bronce que presentan decoraciones con diversos motivos grabados 0 acuñados: medallones centrales con animales o crismones en su interior, zarcillos y cuentas que rodean todo el contorno de la pieza. La producción germa$n a$ se caracterizaría, según Åberg, por presentar decoración damasquinada. Los motivos decorativos pertenecen al llamado "Estilo Animal II", estilo que también se documenta en Europa Central. Los ejemplares del estilo mixto presentan motivos decorati- 

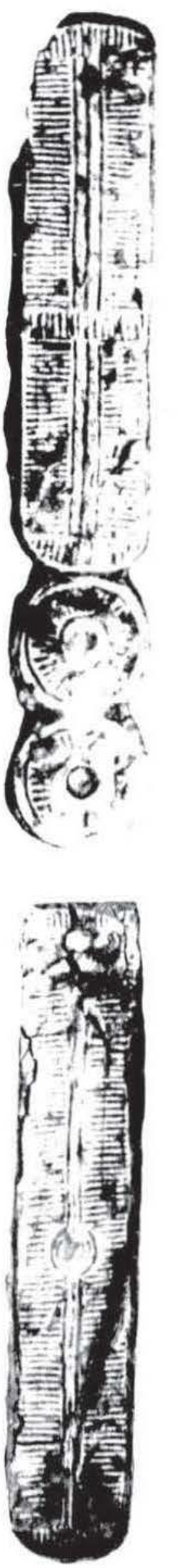
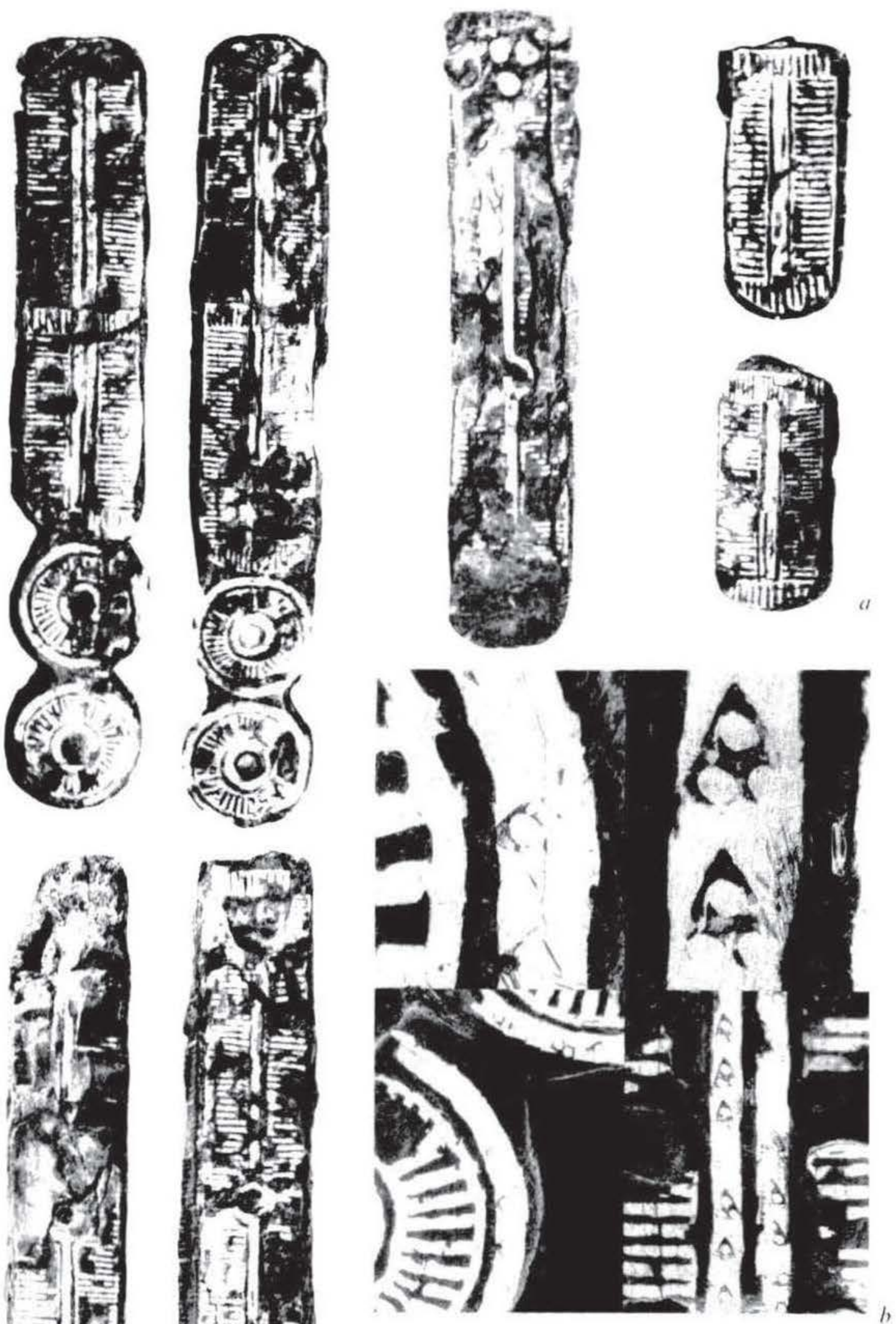

Figura 2. a) Placas verticales, lengüetas y colgantes del cinturón de München-Pasing (Baviera). Escala I: I. segun Stein: b) Placa damasquinada procedente de München-Pasing (Baviera). Foto aumentada, cedida por la Prähistorische Staatssammlung. Munich. 
vos bizantinos realizados con la técnica del damasquinado y motivos decorativos del estilo "Animal II" grabados o acuñados ( $\AA$ berg, 1923, 120-125, 128132 y 135-142).

Joachim Werner (1953) publicó un estudio sobre la necrópolis de Bülach (cantón de Zürich, Suiza). A través del análisis de los ajuares pudo determinar la existencia de varios tipos de cinturón para guardar los puñales. Los fechó a través de la estratigrafia horizontal, cronologia que sirvió de base para estudios posteriores. En esta necrópolis no se documentaron cinturones múltiples, pero se hallaron cinturones con tres placas del tipo denominado «Bülach».

De una cronología más reciente que el tipo «Bülach» son las placas denominadas «Bern Solothurn» que presentan una decoración damasquinada realizada con la técnica de «placage» (damasquinado en áreas) realizada en plata y latón (Fig. 2b). Los cinturones formados por este último tipo se encuentran situados en la periferia de la necrópolis. Junto a éste último tipo Werner menciona el hallazgo de una placa decorada con la técnica de damasquinado que él describió como en decoración en celdillas (Plattiert). Ambos tipos serian contemporáneos. Joachim Werner en 1955, en su estudio sobre el cementerio de Mindelheim (Baviera) pudo observar la existencia de cinturones múltiples compuestos por varios tipos de placas, entre ellas, tres eran alargadas y estaban dispuestas verticalmente. Debido a esta disposición denominó a estas piezas «placas verticales». Además pudo observar que la decoración damasquinada en celdillas era exclusiva de las placas que componían los cinturones múltiples (1955, 11-13).

Rainer Christlein en 1966 distinguió la existencia de dos grupos de cinturones, según la longitud de las placas. Las placas verticales del Tipo A presentan un apéndice en forma de «U» mientras que las del Tipo B se caracterizan por tener un apéndice circular. Ambos tipos A y B tienen distintos motivos decorativos realizados con la técnica del damasquinado. La mayoría de las piezas del tipo B presentan en el reborde un damasquinado de puntos.

A estos grupos pertenecerían las placas con decoración del "Estilo Animal II» (Tierstil II). Los mismos motivos decorativos también se encuentran en las placas del cinturón halladas en Tuggen, Suiza.

R. Christlein pudo distinguir según la estratigrafía horizontal del cementerio cuatro fases (Fig. 3). Fecha las placas colgantes con la mayor longitud (de más de $7 \mathrm{~cm}$ ) al final de la fase III (segundo o tercer tercio del siglo vii d.C.) (Christlein, 1966, lám. 123,2). Para la datación absoluta se basa en el trabajo de $\mathrm{H}$. Zeiss sobre el tesoro de Akalan y en algunos ajuares datados por monedas.
Cree que todo este grupo con decoración de puntos pertenecería a un taller itinerante (Christlein, 1966. 44-60 y 84-85).

Peter Paulsen en 1967, basándose en el trabajo de Zeiss, desarrolla la evolución de los cinturones múltiples hallados en Rusia Meridional, que a través de los ávaros habrian llegado al sur de Alemania y a Italia. El autor supone que las hileras de puntos damasquinados eran una imitación de las hileras de las cuentas acunadas que presentaban los cinturones bizantinos. También considera que los cinturones y especialmente los que presentan motivos animales, que él identifica como serpientes y no como animales fantásticos, podrían ser fabricados sólo para ser depositados en los enterramientos, tendrian por tanto un significado simbólico (Paulsen, 1967, I, 4052; $182-188$; taf. 35,37 y 38 ).

Alessandra Melucco Vaccaro en 1978 reunió las placas de cinturones múltiples aparecidas en Italia, Alemania y Suiza que eran conocidas hasta esa fecha, con ocasión de la restauración de unas placas damasquinadas procedentes de las necrópolis italianas de Nocera Umbra y Castel Trosino. L. Plank en sus investigaciones realizadas sobre el cinturón de tipo Civezzano expuso la posibilidad de que estas placas damasquinadas pudieran haber sido fabricadas en la Italia Longobarda, opinión que posteriormente compartió A. Melucco y que extendió a algunos de los tipos de cinturones múltiples damasquinados.

Melucco Vaccaro, sin emplear los trabajos de Christlein, elaboró una tipología de las decoraciones damasquinadas. Estableció la existencia de cinco tipos: entre ellos el de listeles o celdillas. A este último tipo correspondería la placa de Saucedo. A. Melucco Vaccaro en 1978 confirma la existencia de una analogía cronológica a ambos lados de los Alpes. A través de las fuentes escritas, cree que estos individuos pudieron haber sido funcionarios del Estado con posesión de tierras y de hombres. Poseerían conocimientos de escritura ya que alguno de los cinturones presentan inscripciones con frases que hacen referencia a los textos bíblicos o bien dedicaciones.

b) Intentos de reconstrucción y funcionalidad. La composición de los cinturones múltiples comenzó a ser definida por Lászlo en 1955, le siguieron otros estudios entre los que podemos mencionar los realizados por Moosbruger-Leu (1960) y Christlein (1966). Lászlo reconstruyó los cinturones múltiples aparecidos en sepulturas muy ricas de guerreros ávaros, entre ellos los hallados en Kunágota (Kom. Csanád) y en Ozora (Kom. Tolna), que estarían realizados de la manera siguiente: en el centro una len- 


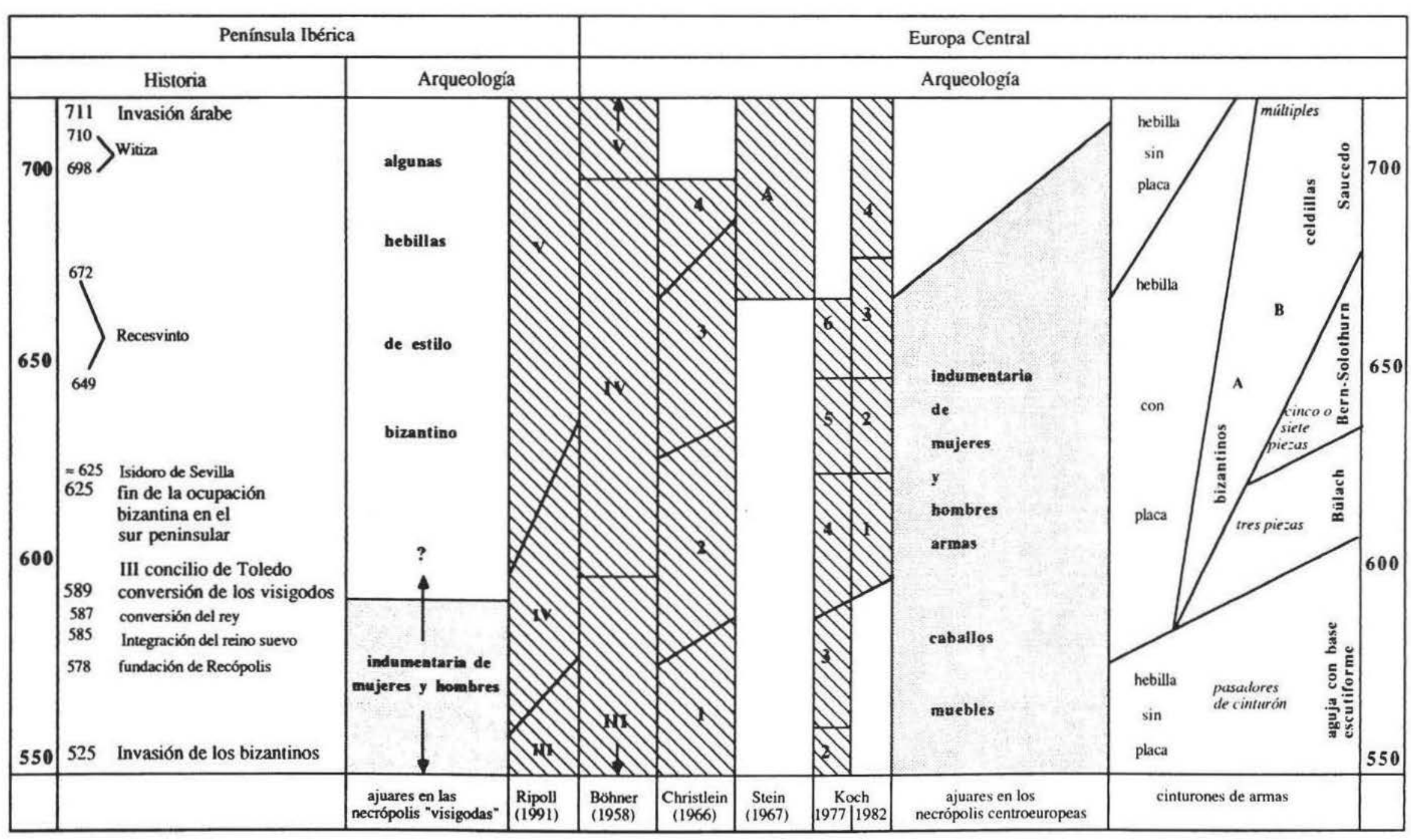

Figura 3.-Esquema cronológico del siglo vı al viI en la Peninsula Ibérica y Europa central, según Sasse. 

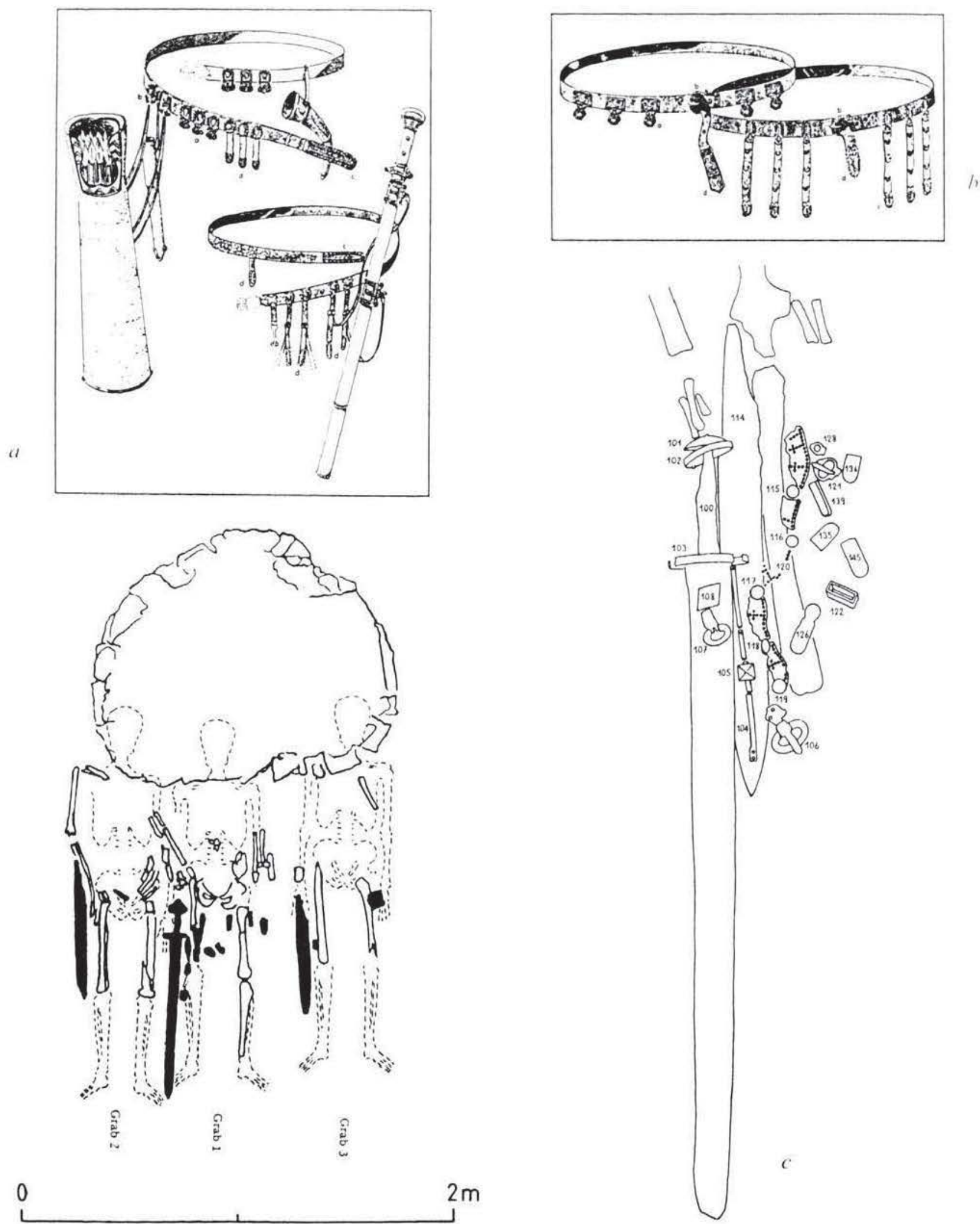

Figura 4.- $a$ y $b$ Reconstrucciones de cinturones múltiples, según Lászlo; $c$ Enterramiento colectivo hallado en el interior de la iglesia parroquial de Tuggen (Kt. Schwyz, Suiza) y ajuar de la sepultura $n^{\circ}$ 1, según Moosbrugger-Leu. 
güeta principal, una presilla y una pequeña contraplaca; a un lado tres placas verticales con apéndices semicirculares y al otro placas colgantes y verticales. Las placas verticales no tendrian como función guardar el puñal, sino una simple función decorativa. El enterramiento de Ozora está fechado a través de una moneda en una etapa posterior al 669-670 d.C. (Lászlo, 1955, 256-261) (Fig. 4, a y b).

Los hallazgos realizados en 1960 por R. Moosbrugger-Leu en la iglesia parroquial de Tuggen ( $\mathrm{Kt}$. Schwyz, Suiza) permitieron conocer algo más sobre la composición de los cinturones múltiples. El descubrimiento consistió en una sepultura colectiva en la que habian sido depositados tres individuos con sus respectivos ajuares (Fig. 4c). En la sepultura número I Moosbrugger-Leu pudo distinguir, gracias a los estudios de J. Werner, la existencia de un cinturón múltiple para guardar el puñal y otro cinturón para envainar la espada. A diferencia de las sepulturas de Mindelheim, esta tumba conservó el cinturón múltiple casi completo, compuesto de al menos veintidós placas. Basándose en la placa decorativa de un escudo encontrado en Stabio (Kt. Tessin, Suiza) (Fig. 5a), intentó reconstruir la composición del cinturón (Fig. $5 \mathrm{c}$ ), hecho que no le resultó fácil porque éste no formó parte de la indumentaria del difunto, sino que se depositó junto a las armas, al lado de una de las piernas. Debido a esta ubicación y a la descomposición del cuero las placas no se conservaron en su lugar original (Fig. 4c). Gracias al hallazgo de algunas láminas metálicas que se conservaron en los remaches de una de las placas verticales halladas en Tuggen, el autor pudo determinar que éstas podian traspasar el cinturón, una tira rematada con una placa pequeña colgante y una segunda tira interpretada como parte de la sujeción del puñal (Fig. 4b).

Rainer Christlein (1966) en sus estudios sobre la necrópolis de Marktoberdorf (Ldkr. Marktoberdorf, Regierungsbezirk Schwaben, Baviera) determinó los siguientes puntos: 1) cinturones múltiples en treinta y seis sepulturas, de éstos sólo cinco presentaban placas con decoración damasquinada; 2) en diecisÉis sepulturas, el cinturón formó parte de la vestimenta del difunto, en claro contraste con lo constatado en las sepulturas descritas anteriormente; 3 ) en la sepultura $n^{\circ} 40$ se pudo ver con claridad que las tres placas verticales se encuentran en posición paralela y con los apéndices hacia abajo (Fig. 5d). Además pudo deducir que éstas estaban colocadas en la espalda del difunto. Debido a esta situación cree que estas placas no tendrian como función sujetar el puñal sino que podrian sostener una bolsa, ya que ésta, por lo general se llevaba colocada en la espalda; y 4) en las tumbas números 40 y 196 (Fig. 6) se encontraron junto a la cadera del difunto dos placas, una con un orificio y otra con dos ganchos. Tanto el orificio como los ganchos pudieron utilizarse para introducir un cordón que sirviera para sujetar la vaina del puñal.

R. Christlein cree que la mayoria de las placas verticales de pequeño tamaño (colgantes) estaban situadas en el lado derecho del cinturón.

Por tanto las placas tendrian la siguiente disposición: las tres placas verticales con apéndices irian en la espalda para llevar una bolsa; las placas con orificio o con ganchos, en el lado izquierdo para sujetar la vaina del puñal; y el resto de las placas pequeñas colgantes irian colocadas en el lado derecho y solo tendrian una función decorativa.

Este investigador observó que los cinturones depositados en las tumbas no presentaban siempre todos los tipos de placas posibles. También pudo deducir que las placas pequeñas colgantes de más de $70 \mathrm{~mm}$ de longitud estaban depositadas en sepulturas que se hallaban en la periferia de la necrópolis, se trataba por tanto de las tumbas más modernas del cementerio.

En su trabajo sobre la necrópolis de Dirlewang (Ldkr. Mindelheim, Baviera) desarrolla más las investigaciones sobre los cinturones múltiples. Las placas halladas en la sepultura $n^{\circ} 38$ le permiten confirmar la distribución asimétrica de las placas colgantes a ambos lados de las tres placas verticales que iban situadas en la espalda (Fig. 7a y 1c) (Christlein, 1971, 26-30 y 52-54).

c) Estatus social de los poseedores. H. Zeiss en 1935 fue el primero que planteó la posibilidad de que las placas de cinturones múltiples debieron formar parte de la indumentaria de los guerreros, $\mathrm{H}$. Zeiss indicó que las placas también se encontraban depositadas en sepulturas ávaras. Su presencia en estas tumbas y los hallazgos de cuños para realizar las decoraciones en Hungría, le permite llegar a la siguiente conclusión: los ávaros habrian transmitido estas formas a la Europa central y a través de los longobardos éstas habrían llegado hasta Italia. (Zeiss, 1935, 17-18).

Frauke Stein publicó, en el año 1967, un trabajo sobre sepulturas halladas en Alemania con ajuares muy ricos fechadas a finales del siglo vil e inicios del siglo viII que fueron identificadas como sepulturas pertenecientes a la nobleza. Estos planteamientos sociales fueron el comienzo de una larga discusión sobre la posibilidad de identificar la posición social de los individuos, a través de los ajuares depositados en las sepulturas (Werner, 1968; Steuer, 1968; Steuer y Last, 1969; Steuer, 1982; Sasse, 1982). 

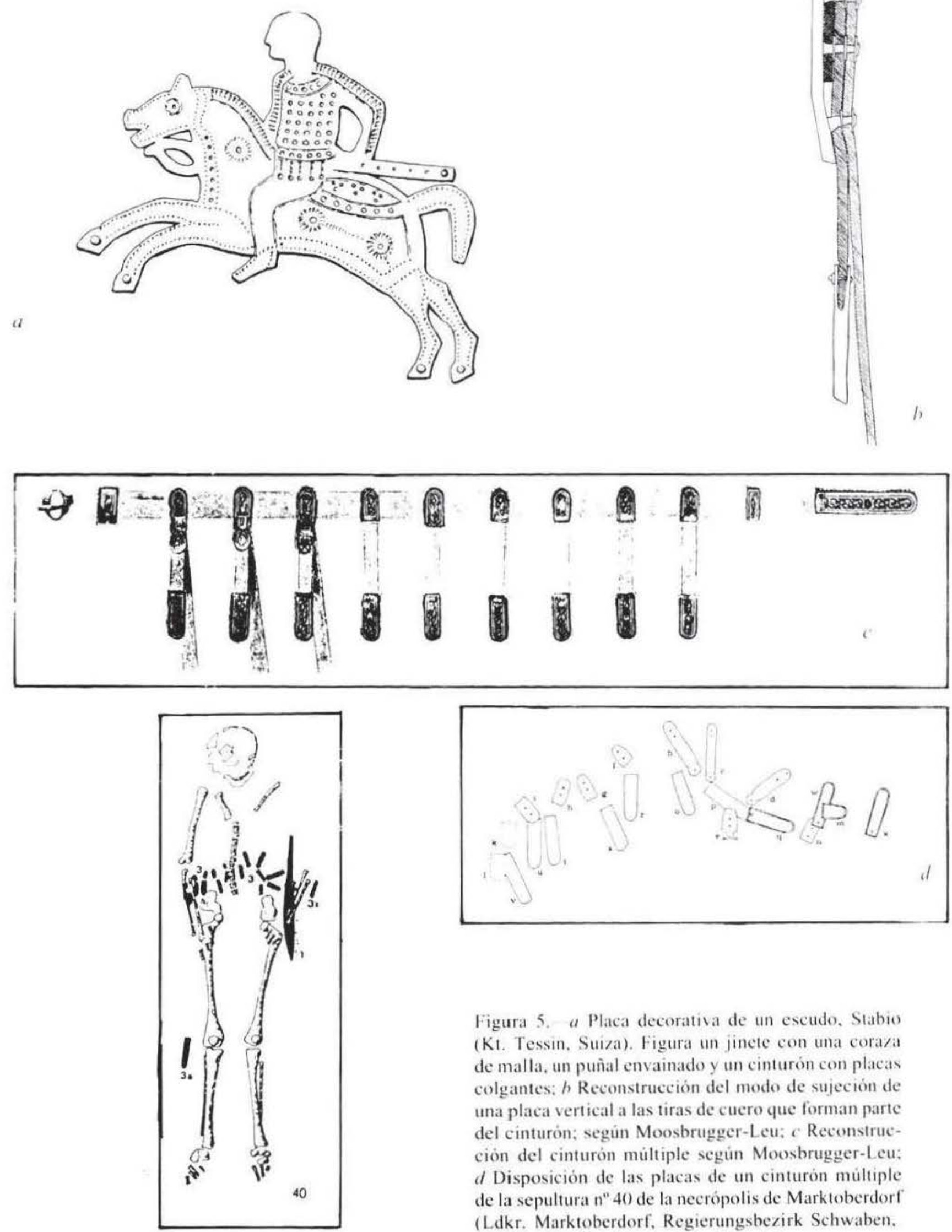

Figura 5. a Placa decorativa de un escudo, Stabio (KI. Tessin. Suiza). Figura un jinete con una coraza de malla, un puñal envainado y un cinturón con placas colgantes: $h$ Reconstrucción del modo de sujeción de una placa vertical a las tiras de cuero que forman parte del cinturón; según Moosbrugger-Leu; $c$ Reconstrucción del cinturón múltiple según Moosbrugger-Leu: $d$ Disposición de las placas de un cinturón múltiple de la sepultura $n^{\prime 4} 40$ de la necrópolis de Marktoberdorf (Ldkr. Marktoberdorf, Regierungsbezirk Schwaben. Baviera), según Christlein. 

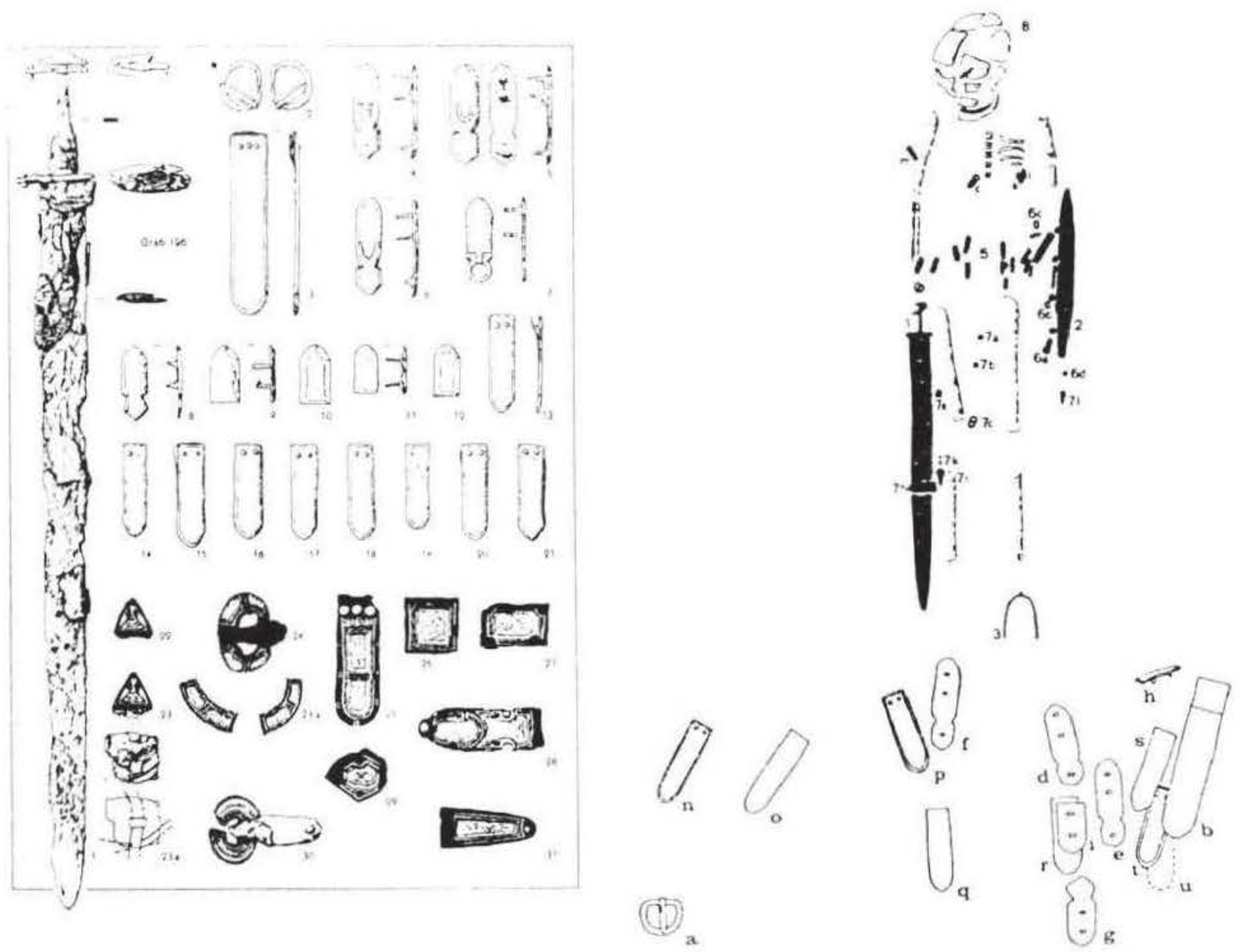

Figura 6. Distribucion del ajuar, disposicion de las placas de un comturon multuple y detalle del ajuar de la sepultura n"196 de la necropolis de Marktoberdol (Ldkr. Marktoberdorf. Regierungsbecirk Schwaben, Baviera). segin Christlein.

En 1967 P. Paulsen dió a conocer una pequeña necropolis hallada en Niederstot/ingen (Alemania). En ella se documentaron tumbas con ajuares tambien muy ricos, sepulturas que fueron identificadas, al igual que en el caso anterior. con la nobleza. En tres de éstas se hallaron cinturones multiples $y$ en dos de ellas se depositaron también armas y arreos de caballo. En la tercera, perteneciente a un niño menor de dos años, sólo se documentó el cínturón.

Es interesante resaltar que todas las placas presentaban en la corrosión del hierro restos de tejidos y plumas. Las placas que formaban parte del cinturón depositado en la tumba infantil conservaban tejidos de lana de diversos tipos: entre los que podemos destacar el denominado entramado de rombos. Los cinturones pertenecen al "Tipo A» identificado por Christlein, aunque Paulsen no cita la obra de este investigador.
En 1985 Uta von Freeden publicó una sepultura hallada en Moos-Burgstall (Niederbayern, Baviera). Esta tumba pertenecia a un guerrero y en su interior se hallaron dos cinturones: uno del tipo "Civerzano" para guardar la espada y otro múltiple del tipo "Tuggen» para envainar el puñal o sax. La investigadora, basándose en el trabajo de Melucco Vacearo, considera que los dos cinturones proceden de talleres ubicados en la Italia Longobarda (Freeden. 1985, 14-15).

d) Cronologia. N. Ảberg en 1923 fechó las piezas procedentes de las necrópolis del norte de Italia a través de un tesoro hallado en Akalan (Catalca, provincia de Estambul. Turquia) que presenta placas de cinturones múltiples bizantinos junto con diversas monedas, las más modernas pertenecientes al emperador Heraclius $(610-641)(1923,120-125,128$ 132 y 135-142). Algunos años despues $H$. Zeiss relacionó el tesoro hallado en Akalan, con placas de 
oro encontradas en Alemania e Italia que posteriormente serían denominadas como placas de cinturón múltiples (Zeiss, 1935, 17-18).

J. Werner llega a través del análisis de la estratigrafia horizontal del cementerio de Mindelheim (Baviera) a la siguiente conclusión: " en las tumbas de este cementerio los cinturones con tres placas son de una fase más antigua y los cinturones múltiples de una etapa más moderna” (Werner, 1955. $11-13)^{3}$.

Stein recopiló en 1967 las tumbas que presentaban, entre los objetos depositados como ajuar, cinturones múltiples decorados con la técnica de «Placage" y entre ellos los denominados en decoración de celdillas; estas sepulturas fueron consideradas como las de cronologia más moderna de las necrópolis de estilo merovingio. Para esta datación se basó en las observaciones realizadas por Werner. La autora observó que las placas de "celdillas" presentaban, muy a menudo, pequeños cabujones de almandines o pequeños círculos realizados en latón. Además algunas de ellas presentaban como decoración láminas rectangulares de plata.

Las placas de celdillas en particular y el cinturón múltiple en general se hallarian sobre todo en la zona oriental con necrópolis merovingias tardias y caracterizarian la fase A de la cronología relativa elaborada por Stein para la Edad Merovingia tardia, mientras que la fase B está definida por cinturones con hebillas simples y lengüetas muy largas (überlang) (Fig. 3) (Stein, 1967, 32-37; Taf. 76.4, 6-9; Taf. 77.1.2.4-10; Taf. 79; Taf. 80, Taf. 81.5, 7-11; Taf. 83. 10-12; Taf. 85. 1-5; 86. 4-9; Taf. 88; Taf. 91. 16-21 y pp. 57-58).

H. Ament, basándose en los estudios de Christlein realiza en 1976 una crítica a la cronología propuesta por F. Stein. Para él existirian dos grupos distintos de armas y cinturones en la fase A de Stein. Los cinturones múltiples pertenecerian al grupo más antiguo. Este grupo se pone en relación con la fase IV de Böhner, fechada por Ament en una época anterior al año 680 (Ament, 1976, 320-321).

La investigadora Ursula Koch a través de las investigaciones realizadas en la necrópolis de Schretzheim (Ldkr. Dillingen, Baden-Württemberg) pudo elaborar una cronología relativa de seis fases que abarca desde el 525 hasta el 680 d.C. En las fases V y VI se documentan cinturones múltiples; las sepulturas que los contienen están situadas en la periferia

3 "Daraus ergibt sich, dass in der Belegung des Gräberfeldes die dreiteiligen Garnituren in einen älteren und die vielteiligen Garnituren in einen jüngeren Abschnitt gehören.» de la necrópolis. La autora observa que el tipo de placas decoradas con celdillas no se documenta por lo que llega a la conclusión de que éstas son posteriores a la fase VI (Koch, 1977, 30-35; 129-131 y taf. 248 y Koch, 1982, 387-474).

P. Paulsen y H. Schach-Dörges en 1978 publicaron la necrópolis de Giengen an der Brenz (Kr. Heidenheim, Baden-Württemberg). Para el estudio de nuestra pieza son importantes las placas de los cinturones con decoración en celdillas o Wabeng Plattiert halladas en las sepulturas $n^{\circ} 10$ y 12 de la necrópolis de Giengen an der Brenz (Fig. 7c). Ambos ejemplares se pudieron fechar a través de la estratigrafia horizontal entre las sepulturas más modernas de la necrópolis (Paulsen y Schach-Dörges, 1978, 105-109 y Taf. 13. D, 8-15; Taf. 16.B, 9-23).

Las cronologias expuestas por Koch (1977) y Schach-Dörges (1978) fueron confirmadas por Christiane Neuffer-Müller en 1983 a través del estudio de la necrópolis de Kirchheim am Ries (Ostalbkreis). Los restos del único cinturón formado por placas decoradas con celdillas procede de una tumba datada en la fase IV de Christlein (posterior al 680). (Neuffer-Müller, 1983, 85-86).

En 1992 Lars Jorgensen publicó un trabajo sobre la cronología longobarda en Italia. En el estudio se presenta la evolución tipológica de las placas de cinturones múltiples. Establece la existencia de cinco fases y en la última, fechada entre el 660-680/90, documenta las placas verticales con apéndices circulares, decoradas con el estilo "Animal Il» (Fig. 9) (Jфrgensen, 1992, 107-117).

e) Tecnología. A. Melucco Vaccaro a través de las restauraciones llevadas a cabo en las piezas de Nocera Umbra y Castel Trosino, pudo conocer la tecnología empleada en la fabricación de las placas. Se confirmaron y precisaron las conclusiones expuestas por Salin (1957), Moosbrugger-Leu (1967) y France-Lanord (Salin y France-Lanord, 1943).

Melucco Vaccaro distingue la existencia de tres técnicas distintas para la realización de la decoración damasquinada: $a$ ) el conocido como "auténtico" (elaborado de dos maneras diferentes); b) Plattierung (damasquinado en áreas), y $c$ ) Bandierung (damasquinado en bandas) (Melucco Vaccaro, 1978, 9-75).

A través de un proyecto dedicado al estudio de los objetos conservados en el Museo de Prehistoria y Protohistoria de Berlín y realizados con la técnica de damasquinado, se analizaron las placas de cinturones múltiples. Los resultados obtenidos en la investigación fueron publicados en 1994 por Gussmann, Born, Riederer, Illerhaus, Goebbels y Riesemeier. 

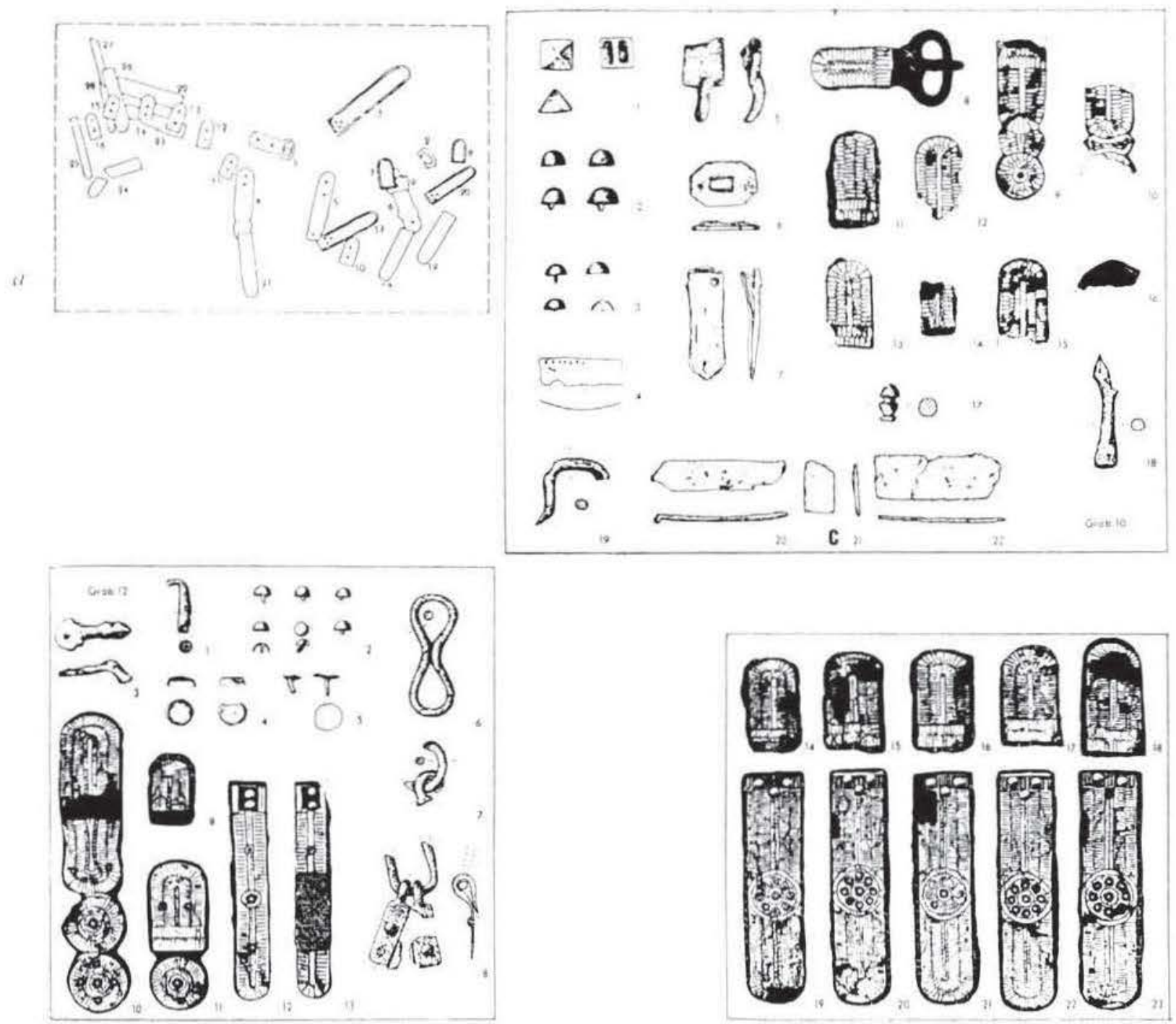

Figura 7. "Placas de cinturon multiple hallado en la tumba n" is de la necropolis de Dirlewang (L dkr. Mindelheim. Baviera): b Njuar de lat lumba n" 10 de (iiengen an der Brenz (Kr. Heidenhem. Baden-Würtemberg). segun Paulsen y Schach-1)örges, y * Ajuar de la tumba n" 12 del cementerio de Giengen an der Brenz (Kr. Ileiden-

heim. Baden-Württemberg). segun Paulsen y Schach-Döges.

Gussmann pudo distinguir varias técnicas de fabricación en los diferentes elementos que componian los cinturones múltiples: las placas verticales presentaban una sola lámina metálica en la que los remaches estaban realizados con soldadura de cobre (Fig. 8, a y b). Las placas colgantes y las lengüetas principales se caracterizaban por presentar dos laminas unidas en su borde a traves de una tira de hierro soldada en cobre; ésta no circunda toda la pieza sino que deja libre el lado recto de las placas con el fin de que se pudiera introducir el cuero del cinturón. Este era sellado a través de presillas (Fig. 8a). En algunas ocasiones se puede determi- nar que los hilos empleados en el damasquinado habian sido retorcidos (Fig. 8c).

El autor especifica los diferentes tipos de damasquinado. los tres primeros ya definidos por Melucco Vaccaro (autentico, en bandas y en áreas) a los que añade otros dos: con puntos y en circulos. En la mayoria de los casos antes de la aplicación de la decoración damasquinada la superficie del hierro fue preparada a través de diversos tipos de incisiones (Fig. 8d). No fue posible conocer si los hilos del damasquinado en áreas estaban a un nivel inferior o igual a la base del hierro (Gussmann. 1994, 111-112 y 135-154, lám. 19, 19 y figs. 17, 18, 21, 22, 23 y 24). 

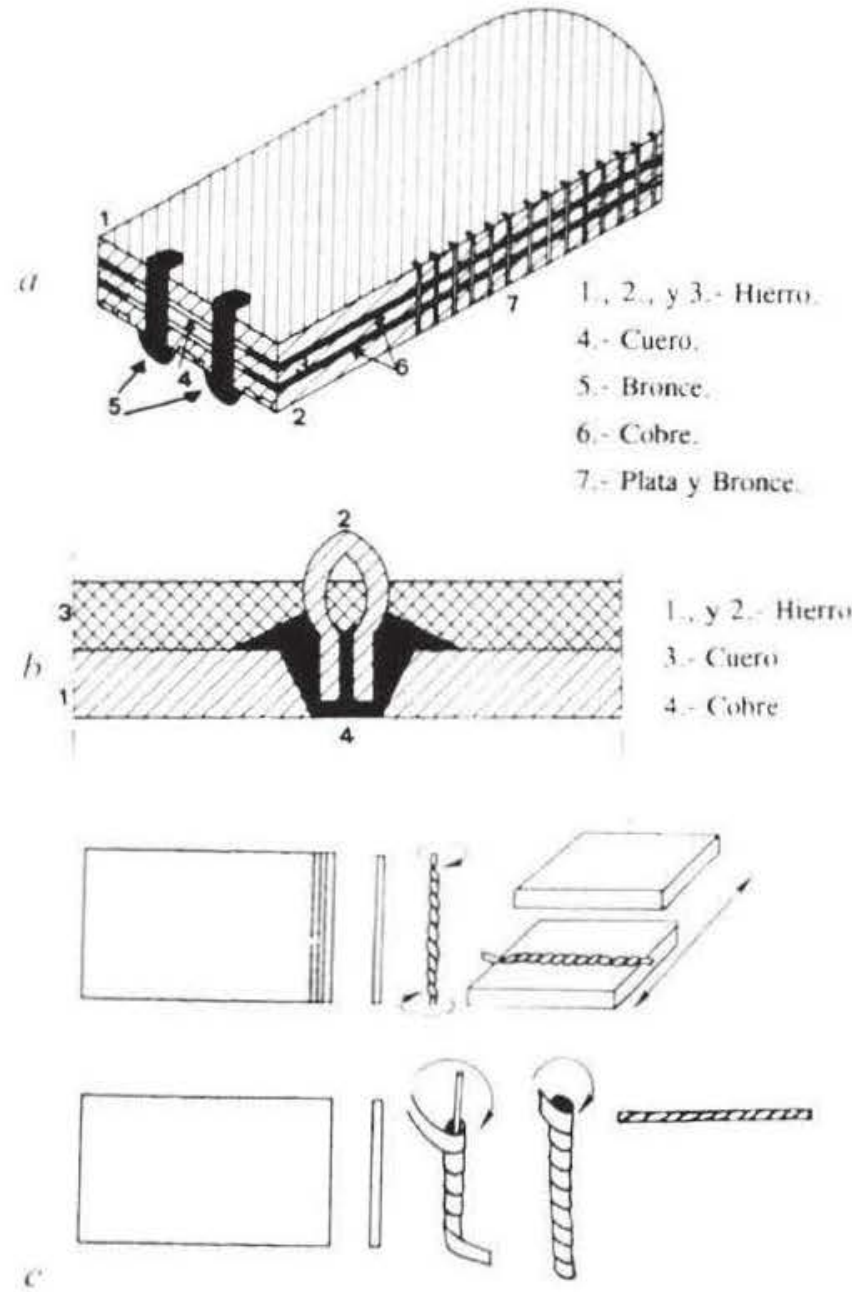

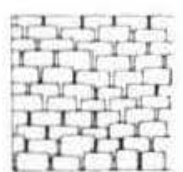

1

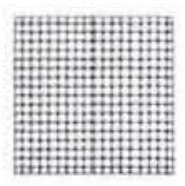

3a

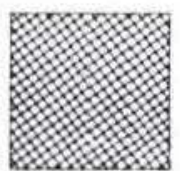

$3 d$

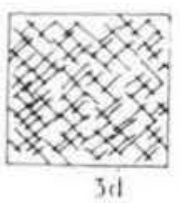

$3 \mathrm{c}$
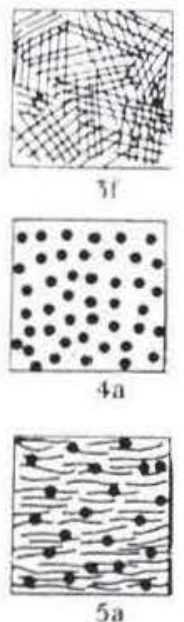

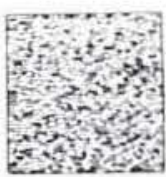

2.1

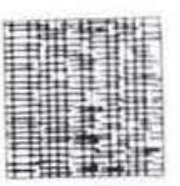

$3 \mathrm{~b}$

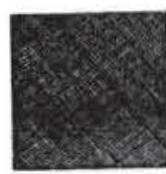

$3 \mathrm{c}$

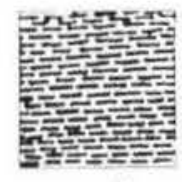

21.

1
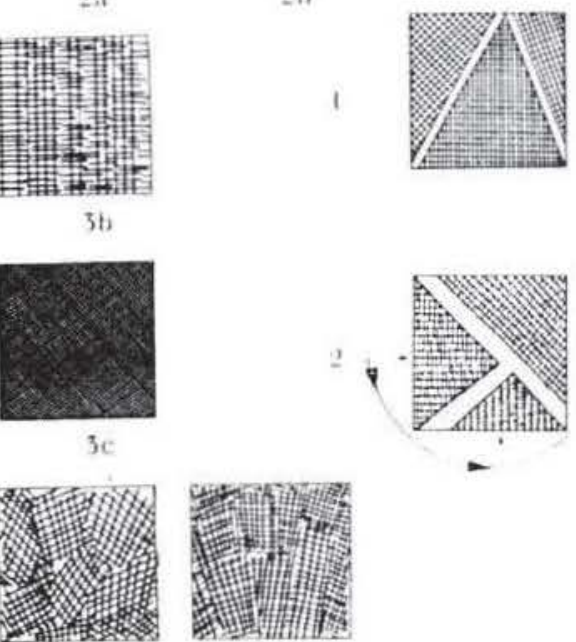

3.

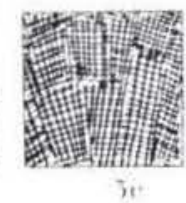

$\uparrow$

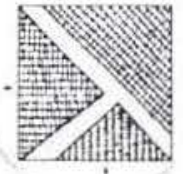

-

Figura $8 . \quad a$ Esquema de fabricación de una lengüeta de cinturón múltiple; $b$ Sección de una placa vertical con remache soldado: $c$ Torsión de un hilo para damasquinado: $y$ d Diversos tipos de preparación de la superficie del hierro. Todos según Gussmann.

A partir de estos análisis. Menghin formuló la existencia de cuatro tipos de técnica damasquinada: el grupo más antiguo que acabaria en el siglo vi presentaria un damasquinado en hilos, el ya mencionado "damasquinado auténtico», y pequeñas áreas damasquinadas sin preparación previa de la base del hierro. Avanzado el siglo vul existirian tres grupos distintos de talleres: el primer grupo trabajó la técnica del "damasquinado en áreas», con la base de hierro trabajada mediante reticulas incisas. Las piezas de este grupo se han encontrado en Francia y en Suiza occidental; el segundo grupo de este siglo vil se ha documentado en el sur de Alemania e Italia y se caracterizaria por producir placas de damasquinado en áreas sin previa preparación de la base. Además están caracterizados por presentar un damasquinado de bandas anchas compuestas por hilos o láminas; el tercer grupo está caracterizado por el uso de hilos que no están retorcidos y por la presencia de un damasquinado en áreas realizado con láminas.

Las placas de cinturones múltiples decoradas con celdillas serian según Menghin damasquinadas con hilos y no con láminas. Menghin utiliza el término "wabentauschiert» (Menghin, 1994, 19-21; 29-31). 

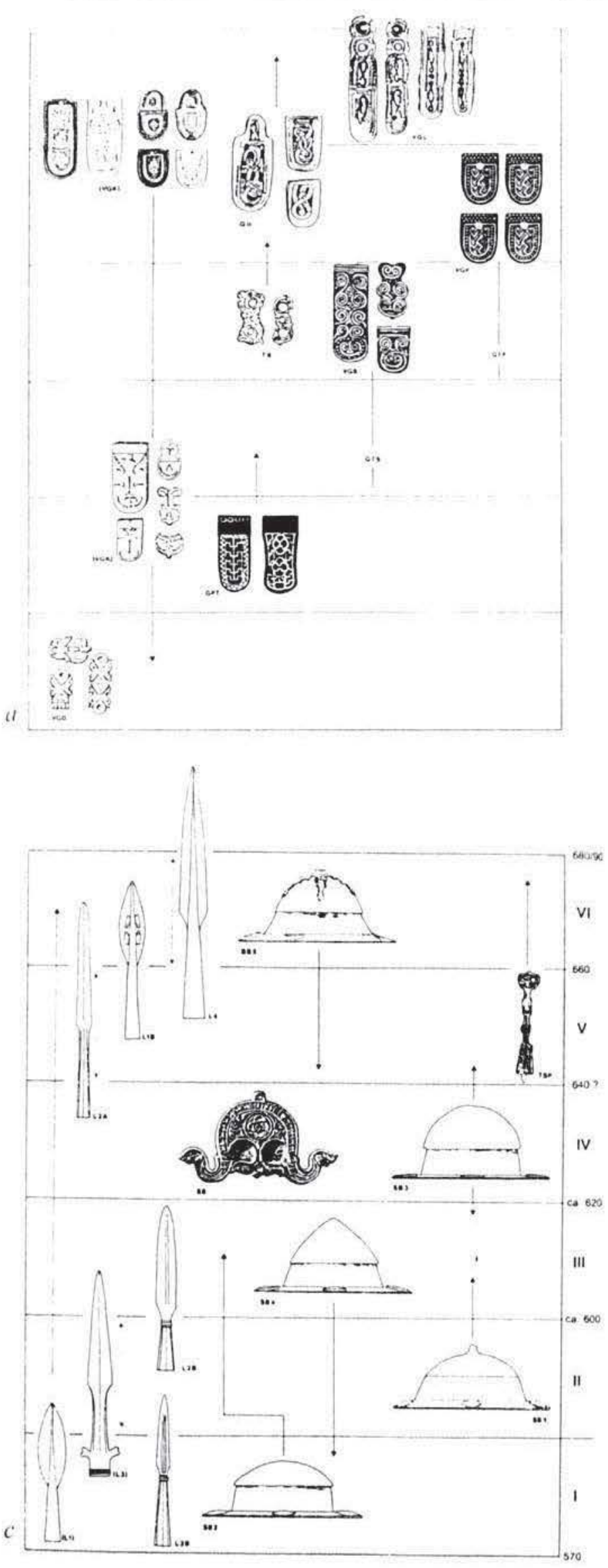

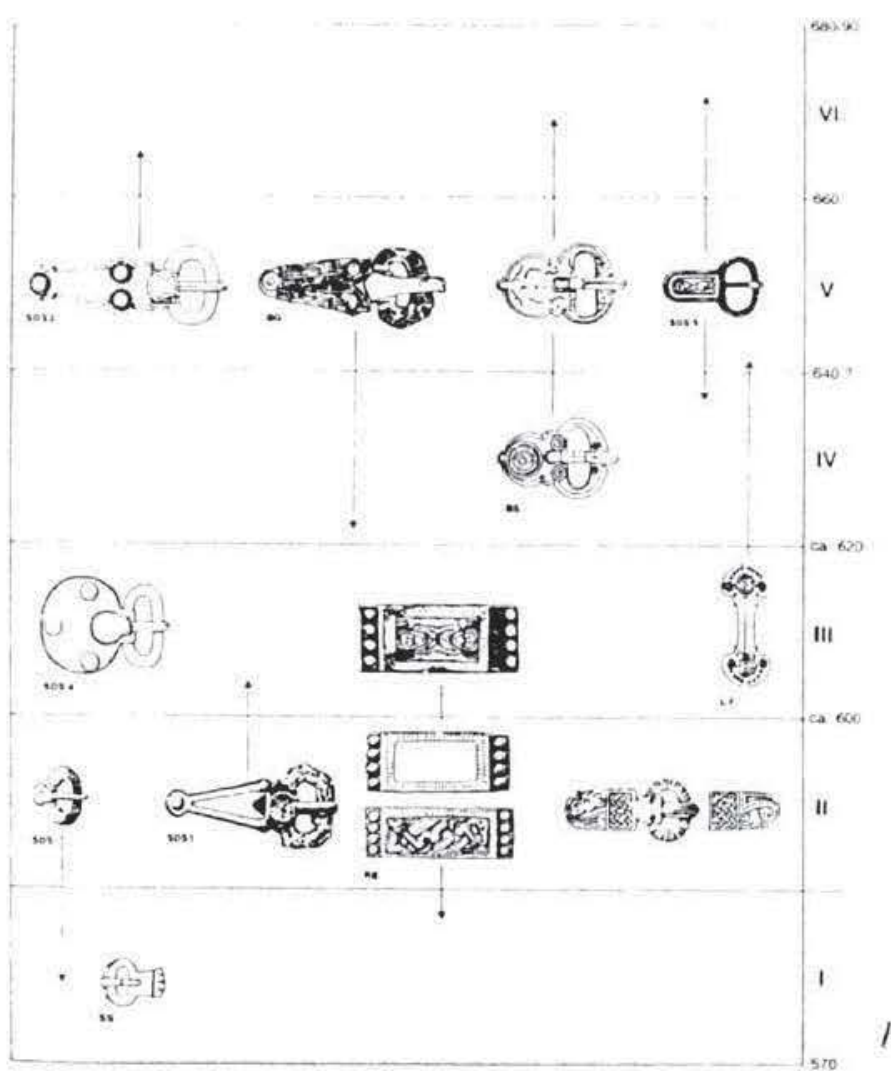

Figura 9. a. b y $<$ Tablas de la cronologia longobarda en Italia, segun Jorgensen.

\section{Evolucion tecnoligica, tipologica it datacion}

El cinturón múltiple empleado en Europa central para guardar el punal, seria la forma más evolucionada de los cinturones empleados para guardar este tipo de arma. Su desarrollo vendria determinado por la evolución tipológica del punal. Este arma ofensiva se caracterizo por tener en el siglo $\mathrm{v}$ y durante gran parte del siglo vi una longitud menor que los ejemplares documentados a finales del siglo vi y durante todo el siglo vil.

El cinturón para el puñal corto, kurz, y estrecho, schmal, con una longitud total menor de $50 \mathrm{~cm}$ y una anchura entre 3 y $4 \mathrm{~cm}$, se caracterizaba por ser estrecho y presentar tan sólo una hebilla sin placas (Fig. 3).

El punal ancho, breit, que solía presentar unas dimensiones entre 3,3 hasta $5,8 \mathrm{~cm}$ de anchura y entre $27-52 \mathrm{~cm}$ de longitud, requeria un cinturón más ancho con hebilla y placas. Los cinturones pertenecientes a este segundo tipo se caracterizaron en los primeros momentos por tener tres placas, una unida a la hebilla, otra afrontada a ella y una tercera situada en la espalda. Los ejemplares más modernos de este tipo de cinturón presenta- 
ban algunas plaquitas de diversas formas entre 3 y 5) que sirvieron para llevar colgados algunos utensilios.

A lo largo de la existencia del puñal ancho. la evolución tipologica del cinturón presenta dos vertientes: una en el oriente de la Luropa central incluida ltalia) en la que se documenta el cinturón multuple y la otra en el oeste de Luropa central (incluido el reino merovingio) donde se desarrollo el tipo de einturon formado por tres placas

Fxecpetomalmente en la zona de Würtemberg y Suiza se documentan al mismo ticmpo los dos tipos de cinturon. Al final de la evolucion documentada por los Reihengräberfelder . los cinturones müliples desaparecen, para dar paso a otros cinturones con una hebilla y una sola lengüeta muy larga. EI punal se caracteriza nuevamente por ser más ligero y corto o estrecho y muy largo. lang.

El desarrollo del cinturón múltiple fue realizado por Christlein quien se dió cuenta de que la longitud de las placas, y especialmente la de las placas verticales, aumentaba con el paso del tiempo. Observo, tambien, que se producia un cambio tanto en las formas como en las decoraciones. Las placas verticales del tipo A de (hristlein presentaban una forma en $\alpha U n$ invertida con un pequeno apéndice también en "U». Este tipo, con frecuencia, presentaba una decoración damasquinada formando espirales.

Una forma más evolucionada la encontramos en el tipo de Tuggen (tipo B de Christlein). El cinturón estaba compuesto por placas verticales tambien en forma de "U» invertida, pero en esta ocasión más alargada que en los ejemplares anteriores, rematadas por un apendice también en "U»", aunque en esta ocasion más cerrada. Tiende a ir formando un apéndice circular. La decoración era damasquinada del llamado estilo Animal II. Junto a estos motivos decorativos podemos encontrar, en la mayoria de las placas, una decoración realizada a base de puntos. motivos que también se documentan en la placa hallada en Saucedo.

Christlein no incluyó en su clasificación las placas decoradas con celdillas (Fig. 10), ya que éstas no formaban parte de los ajuares depositados en las tumbas que él empleó para realizar su sistematización.

J. Werner a través del análisis de los hallazgos procedentes de Bülach (Suiza), pudo observar que una placa damasquinada con decoración de celdi-

\footnotetext{
- Este término se emplea para designar una serie de necrópolis altomedievales que se caracterizan por presentar tumbas dispuestas en hilera en su mayoria con ajuar, y con orientación esteoeste (Reinecke, 1925).
}

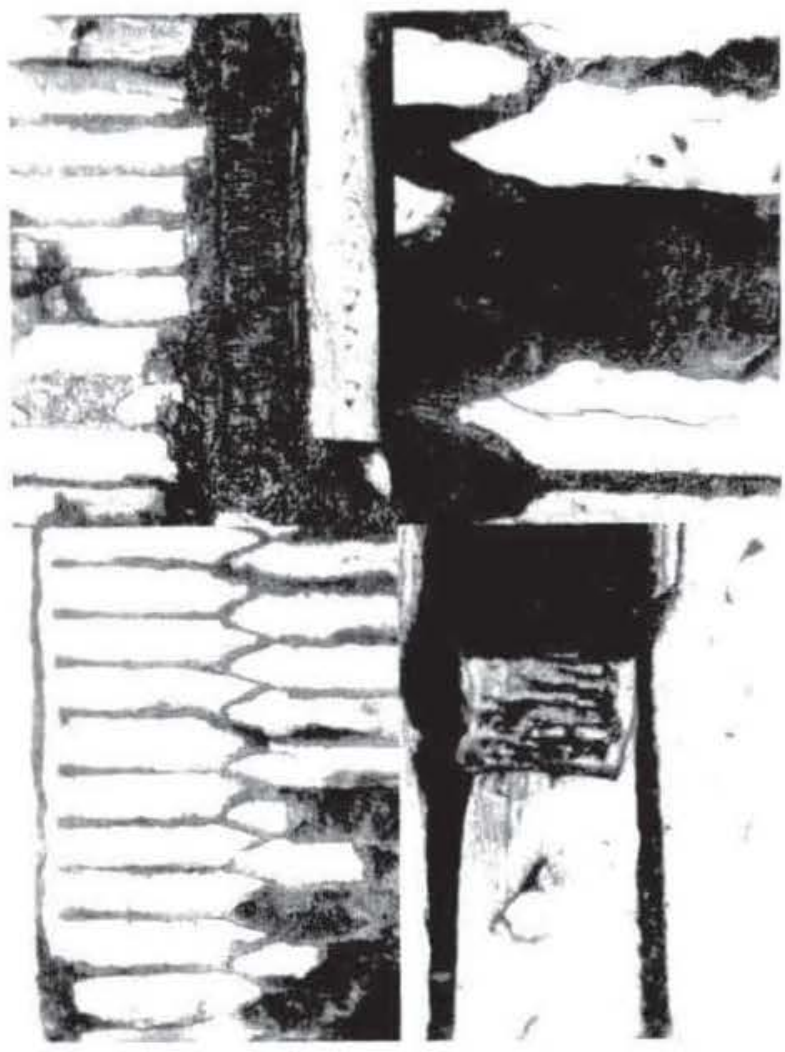

Figura 10. Placa decorada con celdillas procedente de Weilheim (Baviera). Foto aumentada, cedida por la Prähistorische Staatssammlung. Munich.

llas apareció junto a otras que eran caracteristicas del tipo más moderno de cinturón de tres placas. Es interesante resaltar que en la sepultura número 167 un cinturón del tipo "Bern Solothurn" se combinó con una placa alargada (de un cinturón mủltiple) decorada con damasquinado en celdillas y cabujones de almandines o vidrio. Por tanto las placas del tipo «Bern Solothurn" y las decoradas con celdillas serian contemporáneas.

Werner se da cuenta que esta placa presenta paralelos en la zona de Alemania meridional y utiliza la decoración de pequeños cabujones, que estas piezas alemanas presentan para datar el tipo «Bern Solothurn" a finales del siglo vil o inicios del siglo vin. Este autor cita el hallazgo de una fibula en Bermersheim (Rheinhessen) también decorada con pequeños cabujones, pieza que le parecia muy bien fechada al haber aparecido junto a una moneda de Childebert III (695-7I1), cronologia que posteriormente fue modificada (660-662).

Las placas con decoración en celdillas se documentan junto a placas con decoración realizada a base de lineas paralelas en disposición vertical, ho- 
rizontal y radial (Figs. 1a y b, 2a y 11). Ambos tipos de placas presentan las mismas formas y el mismo esquema decorativo incluidos los pequeños cabujones de almandines o vidrio, lo único que varia es la técnica de realización. Por esta razón creemos que estos dos tipos son contemporáneos.

Las placas decoradas con láminas en disposición vertical, horizontal y radial las denominaremos a partir de ahora tipo Saucedo.

Hemos podido observar cómo en muchas de las necrópolis que presentaban depositados en sus tumbas cinturones múltiples, aquellos que tenian una cronologia más moderna eran los denominados «tipo Tugger o Christlein Tipo B».

En aquellas necrópolis donde también se documentó la existencia de placas decoradas con celdillas, se pudo determinar que éstas eran de una cronologia posterior al tipo Tuggen (Paulsen y Schach-Dörges, 1978, 105-109 y Neuffer-Müller, 1983, 85-86).

Esta cronología se puede también confirmar a través de la evolución tipológica: las placas verticales decoradas con celdillas y las del "tipo Saucedo» presentan dos apéndices circulares y sin embargo las del tipo Tuggen se caracterizan por tener un solo apéndice con forma oval. Las placas "Tuggen» serian una evolución de las placas con apéndice en forma de "U» y a partir de ellas se desarrollaron las de apéndice circular.

La datación absoluta del cinturón múltiple se basa en los estudios de Zeiss quien por primera vez lo pone en relación con el hallazgo del tesoro de AkaIan (Zeiss, 1935, 17-18).

Christlein sitúa los cinturones múltiples en su fase III que data a través de las monedas del emperador Heraclio (610-641) encontradas en Akalan (Christlein, 1966, 44-60 y 84-85). En sepulturas merovingias de época tardia se han encontrado muy pocas monedas y las halladas forman parte de sortijas o collares, por lo que no sabemos si éstas estaban o no en circulación en el momento de ser depositadas en los enterramientos.

Christlein para datar más precisamente su fase III cita el hallazgo de nueve anillos, de ellos sólo cuatro se encontraron depositados en el interior de las tumbas.

La sepultura masculina $n^{\circ} 4$ hallada en 1891 en el cementerio de Pfahlheim (O. A. Ellwangen, Württemberg) (Werner, 1935, 100, $\mathrm{n}^{\circ} 46$ ) y una sepultura femenina de la necrópolis de Wonsheim (Kr. Alzey, Rheinhessen) (Werner, 1935, 102, $\mathrm{n}^{\circ} 48$ ) presentaron respectivamente una sortija con moneda de $\mathrm{He}-$ raclio (610-641),

La sepultura de Pfahlheim es de gran interés para nuestro estudio ya que contenia placas colgantes de un cinturón múltiple del Tipo A de Christlein y placas damasquinadas con decoración de espirales pertenecientes al atalaje del caballo; este tipo de decoración se halla también en placas del tipo $\mathrm{A}$ que forman parte de cinturones múltiples.

La sepultura masculina $n^{\circ} l$ de Au (Gem. Rehling. $K r$. Aichach-Friedherg) contenia una moneda que en un primer momento fue identificada por Christlein como un anillo y que posteriormente Stein y Dannheimer lo interpretaron como un colgante (Fig. 11). La moneda en cuestión se trataba de un sólido de Constans II y Constante IV. Durante las investigaciones realizadas por Stein, Christlein y Ament, la moneda fue datada entre los años 659-668. En 1981 Hahn realizó un corpus de monedas bizantinas. Tras su publicación $\mathrm{H}$. Overbeck dió una nueva cronologia del sólido de Au. Cree que perteneceria a Constans II, Constancio IV, Heraclio y Tiberio (659-662) (Stein, 1967, 219-220 y Taf. 76, 1-9; Leinfelder, 1951/52, 290; Kellner,1956, 129 y Dannheimer, 1988, 32-33).

La sepultura femenina $n^{\circ} I$ de Bermersheim $v$. d. H. (Kr. Alzey-Worms) presentaba un anillo con un sólido de Childebert identificado como hijo del Maior Domus Grimoald. La moneda está datada en 660-662 (fue fechada por Werner entre los años 696711).

La moneda hallada en la sepultura de Au data las placas decoradas con celdillas y una uhebilla» con placa rígida decorada con hilos horizontales y verticales, decoración documentada en la placa denominada "tipo Saucedo» (Fig. la y b). Nosotros pensamos que esta «hebilla" pudo formar parte de un cinturón con placas del tipo Saucedo.

H. Ament en su trabajo sobre cronologia tardia merovingia cita otras sepulturas con monedas de reyes merovingios y anglosajones cuya cronología no se conoce con precisión pero que pueden datarse a los largo del siglo VII. Este autor confirma la cronologia del final de la fase III de Christlein o fase IV de Böhner datadas en torno al año 680 veinte años después al 662 (Ament 1976, 320-321 y 323-334).

En las sepulturas que estudió Christlein no se documentaron placas de cinturones múltiples decoradas con celdillas o del llamado «tipo Saucedo", por lo que definió su fase IV por la desaparición de los cinturones múltiples. Para este investigador los cinturones para envainar el puñal sólo presentaban una hebilla tanto al comienzo como al final de su evolución (Christlein 1966, 21 y 1971, 30-32). Sin embargo en otros cementerios sí se documentó el hallazgo de placas de celdillas y «tipo Saucedo», 

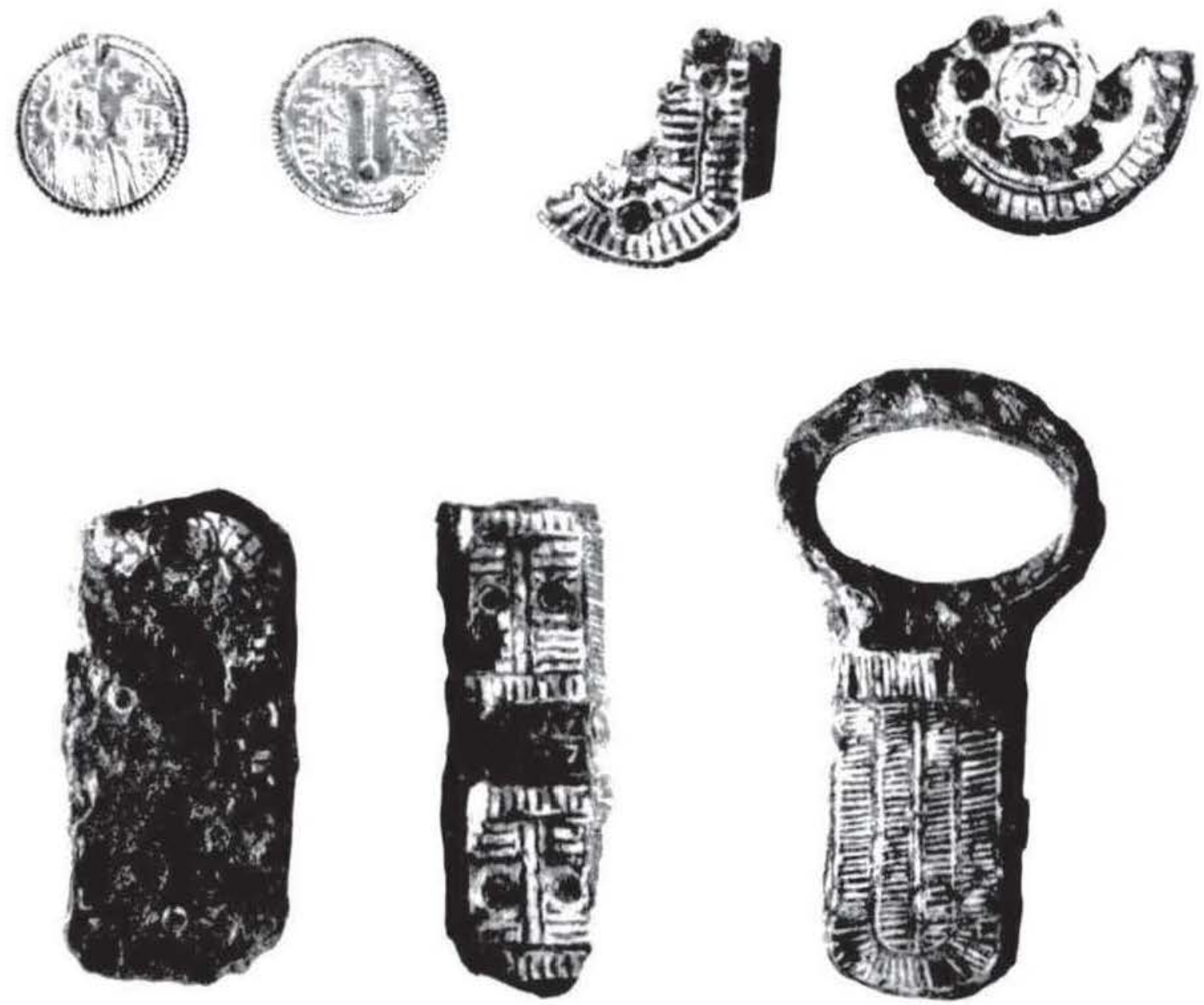

Figura 11.-Hallazgo de Au (Baviera), Escala 1:1., según Stein.

placas que pertenecian a las tumbas más modernas (Schach-Dörges 1978, 105-109 y Neuffer-Müller 1983, 85-86). Esta conclusión está confirmada a través del hallazgo en una tumba de München-Pasing que contenia un cinturón múltiple con placas del denominado "tipo Saucedo". Por tanto es posible que los cinturones con una sola hebilla y los cinturones con placas de celdillas y de tipo Saucedo hayan sido contemporàneos, aunque el uso de estos últimos no habria estado muy extendido. Tan sólo se localizarian en algunas necrópolis.

En conclusión este tipo de cinturón múltiple seria el más moderno, teoria que viene a confirmarse a través del hallazgo realizado en la necrópolis de $\mathrm{Au}$, donde se documentó la moneda de cronologia más reciente de todas las conocidas y halladas en sepulturas merovingias.

Si tenemos en cuenta que esta moneda fue utilizada como un colgante y que no sabemos la edad a la que murió el individuo que la poseia, pensamos que debie- ron pasar muchos años después de la acuñación de la moneda, por lo que la cronologia que poseemos es una cronologia post quem 662 d.C. (Steuer 1977).

La moneda más moderna hallada en el yacimiento de Saucedo pertenece al reinado de Witiza (698-710), cuya fecha podria indicarnos la cronologia ante quem de la placa.

Esta fecha ante quem es importante para la datación ya que un año después se produjo la llegada de los árabes a la península ibérica. A partir de esta fecha parece muy probable que cesaran los contactos entre el centro y sur peninsular y el mundo merovingio y longobardo.

Disposición espacial de las placas de cinturón en el interior de los enterramientos merovingios

En muchas sepulturas masculinas encontradas en necrópolis de Baviera, Württemberg y Suiza se po- 
dia observar la presencia de diversas placas depositadas en la cintura, muy próximas al puñal. A través de minuciosos estudios se pudo determinar que estas placas presentaban diversas formas (hebilla, lengüeta principal, colgantes, verticales) (Fig. 1c) y en aquellos casos en que fue posible comprobarlo, se pudo ver que éstas casi siempre se encontraban en la misma posición. Todos los cinturones presentaban tres placas con apéndices. Estas en disposición horizontal se encontraban situadas en la espalda del difunto y con los apéndices hacia abajo. La placa de Saucedo es una de estas piezas, denominadas como placas verticales. Cuando los cinturones múltiples no formaron parte de la indumentaria del difunto, sino que fueron depositados después, se pudo apreciar con claridad la posición de la hebilla y de lo que hemos denominado lengüeta principal, que siempre se encuentran en posición contrapuesta.

Es interesante resaltar que muchos cinturones carecian de hebilla, por lo que el cinturón pudo abrocharse de otra manera. Algunas piezas identificadas como hebillas nunca llevaron aguja por lo que éstas podrian haber tenido una disposición vertical y servir para sujetar algún utensilio o el puñal.

Esta suposición se confirma puesto que las lengüetas principales a menudo son mayores que la abertura de la hebilla. U. Koch observó que en la tumba $\mathrm{n}^{\circ} 30$ de la necrópolis de Herbolzheim (Kr. Heilbronn) aparecía una pieza metálica interpretada como una presilla para pasar la lengüeta principal. En esta tumba se documentó también una hebilla que fue considerada como un elemento secundario del cinturón múltiple (Koch, 1982, 460 , lám. 34).

A través de la posición que presentan todas las piezas depositadas en la tumba $n^{\circ} 40$ de Marktoberdorf, se puede reconstruir la disposición en la que fue colocado el cinturón. Se observa que todas las piezas con dos remaches situados a la misma distancia, estaban unidos a la correa del cinturón (Fig. 5d).

Las piezas denominadas como colgantes estaban compuestas por dos tipos de placas. Las primeras son de pequeño tamaño con dos remaches que irian unidas al cinturón. De ellas partía una tira de cuero que estaba rematada en su extremo final por el segundo tipo de placa caracterizado por tener una mayor longitud (Fig. 1c). En esta tumba también se pudo apreciar que seis placas colgantes estaban situadas al lado derecho de las placas verticales y sólo dos se encontraban en el lado izquierdo.
Contexo social de los cinturones miltiples de decoración damasquinada

Como se puede ver a través de la historia de la investigación, era común que las sepulturas con cinturones múltiples tuvieran un puñal o sax, el arma más común de los hombres de la época merovingia. Por ejemplo en la necrópolis de Eichstetten (BadenWürttemberg) cerca del $80 \%$ de los hombres adultos poseia un $s a x$, sin embargo pocos eran los cinturones que presentaban decoración damasquinada (Sasse, 1989 y Sasse, e.p).

A través de este dato podemos observar que este tipo de decoración está documentada principalmente en sepulturas que contenian otras armas además del puñal: espadas, umbos de escudos, espuelas, atalajes de caballo, etc.

Christlein en su estudio sobre la calidad que poseian los ajuares definió los atalajes de caballo como caracteristicos de enterramientos muy ricos (grupo cualitativo C. Christlein, 1973, 147-180). En la necrópolis de Eichstetten se pudo observar cómo los umbos de los escudos aparecían solamente en las sepulturas más ricas de este cementerio pertenecientes según la terminologia de Christlein, al grupo cualitativo B. Se incluyen por tanto en las sepulturas más ricas del grupo $\mathrm{B}$.

De gran interés para valorar los cinturones tipo Tuggen o los cinturones con celdillas debemos mencionar algunas sepulturas como por ejemplo la sepultura $n^{\circ} 6$ de Niederstotzingen (Baden-Württemberg) con un cinturón múltiple damasquinado y un cinturón de tipo Civezzano para guardar la espada, un umbo de escudo, una lanza y atalajes de caballos. Muy semejante a esta sepultura es la tumba $n^{\circ}$ 26 de Giengen an der Brenz (Baden-Württemberg). En las dos necrópolis Niederstotzingen y Giengen se conservaron restos de diferentes tejidos y plumas (Hundt, 1978, pp. 149-163) Tenemos que recordar la ya mencionada sepultura de Tuggen (Suiza) en la que los hombres ricamente armados están sepultados en una pequeña iglesia. La misma riqueza se documenta en los enterramientos de Ascheim (Baviera) y en los de Dürbheim (Baden-Württemberg). En los tres últimos casos se trataría de una pequeña necrópolis de la élite que tendria una función militar.

Muy importante para esta interpretación nos parecen los cinturones múltiples encontrados en enterramientos infantiles, de pequeño tamaño pero con una rica decoración damasquinada muy semejante a la representada en los cinturones de los adultos. 


\section{LA TÉCNICA DE PRODUCCIÓN DE LAS PLACAS CON CELDILLAS Y LAS PLACAS DEL TIPO SAUCEDO}

Entre las piezas bávaras y la placa de Saucedo existen pequeñas diferencias en cuanto a la decoración, pero éstas a simple vista no parecen importantes. Sin embargo, si se quiere responder a la pregunta de si la placa de Saucedo procede o no del mismo taller o por lo menos del mismo grupo de talleres que produjeron las piezas bávaras nos parece necesario analizar la técnica de damasquinado. Se deben tener en cuenta los resultados obtenidos por las investigaciones de Melucco Vaccaro y Gussmann que les permitieron conocer los distintos tipos de damasquinado que podrían presentar las piezas.

Las placas con celdillas así como las de tipo Saucedo presentan en su anverso, por lo general, una decoración de damasquinado en bandas. Los análisis de las placas pertenecientes a los dos tipos conservadas en la Prähistorische Staatssammlung de Munich y realizados con un microscopio que permite ver los objetos aumentados hasta 70 veces su tamaño natural, demuestran que las bandas horizontales de las celdillas que componen la decoración son en realidad un damasquinado realizado con dos o tres hilos. Esta variante es técnicamente idéntica al denominado "damasquinado en áreas». Las bandas verticales de la pieza analizada que probablemente procede de-Weilheim (Baviera) podrian ser producto de una sola lámina (Fig. 10). Las decoraciones circulares externas que presentan los apéndices de la placa procedente de München-Pasing están compuestas por dos láminas. Es difícil apreciar si los hilos empleados en la decoración de esta pieza fueron o no previamente retorcidas, como Gussmann habia observado en otros ejemplares.

La estructura que se constata en las decoraciones horizontales y radiales es muy extraña. Los motivos radiados se realizan con hilos dispuestos en círculos concéntricos, por eso se observan fisuras circulares. En la parte superior de la pieza se documentan fisuras verticales entre las líneas en disposición horizontal que demuestran que la plata fue colocada en hilos verticales.

Se podría suponer que se trata de una decoración englobada dentro de la primera variante del damasquinado en áreas y bandas.

A manera de hipótesis proponemos el siguiente proceso de realización: el primer paso consistiria en la preparación de la superficie del hierro (Fig. 12a), con un punzón se marcarían los círculos concéntricos y los motivos radiales (Fig. 12b). Una vez hecho el diseño se trabajaría con la técnica del damas- quinado en áreas; sobre las incisiones realizadas, como ya dijimos mediante punzón, se colocarian los hilos que eran presionados con los dedos, ya que no se observan evidencias del uso de un martillo. Por último se quitaría los restos de la plata de aquellas zonas que no habian sido previamente preparadas. Las bandas anchas verticales de München-Pasing también se componen de algunos hilos paralelos (Fig. $12 \mathrm{~b})$. Todas las piezas analizadas en Munich presentaban superficies previamente preparadas para recibir el damasquinado. Las bandas anchas de la placa de Weilheim? presentaban como preparación dos lineas incisas paralelas que enmarcaban líneas horizontales (Fig. 10).

La decoración que tienen los rebordes de todas las placas presentan la técnica denominada "damasquinado auténtico o damasquinado de hilos».

La placa de Saucedo parece estar elaborada con una técnica distinta a la de los ejemplares bávaros. Según los análisis llevados a cabo por el Dr. Rovira se puede suponer que el damasquinado en bandas estaria realizado mediante láminas simples (Fig. 12c). Sin embargo al igual que en las piezas de MünchenPasing las bandas radiales del apéndice más externo presentan algunas fisuras transversales. La superficie sobre la que se colocaron las láminas horizontales está previamente preparada con incisiones transversales, la zona donde se colocó la lámina ancha vertical presenta por su parte dos líneas incisas longitudinales. Los puntos que alternan con las láminas radiales estaban realizados con la misma técnica que los ejemplares centro-europeos analizados por Gussmann (1994, 146).

\section{CONCLUSIONES}

La placa de Saucedo, hasta ahora única en la Península Ibérica, ha sido identificada como una de las tres placas verticales de un cinturón múltiple. Está ricamente decorada con la técnica de damasquinado y pertenece al grupo de los cinturones con placas decoradas con celdillas, grupo que puede fecharse a finales del siglo vil o inicios del vIII. Las tres placas verticales con los apéndices circulares hacia abajo estaban colocadas en la parte posterior del cinturón. Tenían casi seguro la función de sujetar una bolsa. En uno de los laterales del cinturón se guardó el puñal o sax. En este período y concretamente en Europa central se pudo demostrar que cinturones múltiples con placas ricamente decoradas con damasquinado aparecían con gran frecuencia en sepulturas de hombres con ricos ajuares compuestos por armas y atalajes de caballos. 


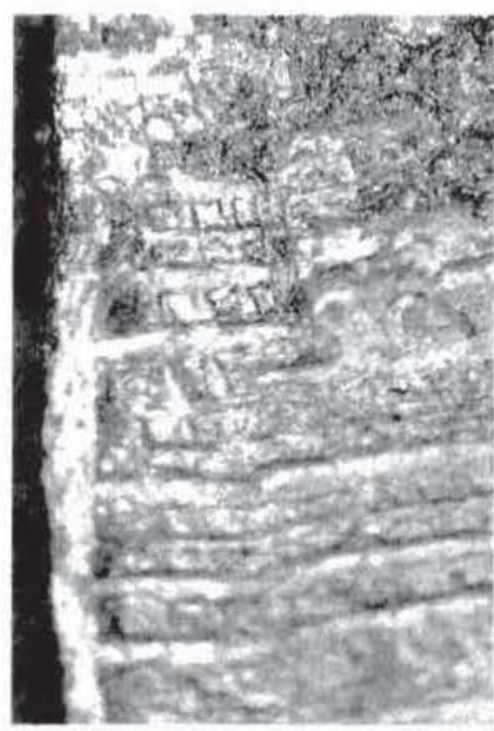

(l)

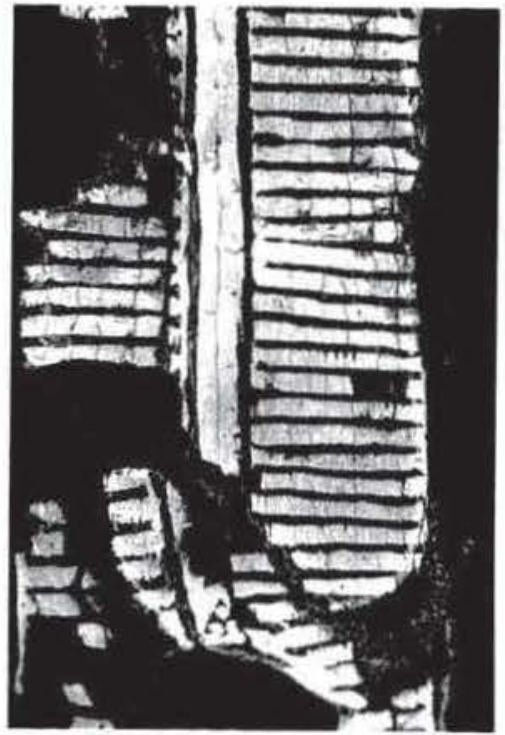

b

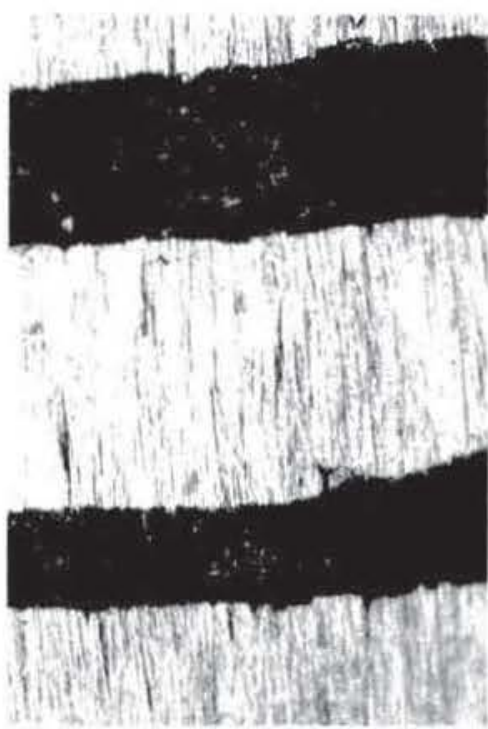

Figura 12. a foto aumentada del reverso de uno de los hilos empleado para la elecucion del damascumado Se aprecian las huellas de la preparación de la superficie de hetro. tratamiento previo a la aplicacion del damasquinado. Placa damasquinada de München-Pasing. b Detalle de la lengüeta principal en la que se puede apreciar la lamina central realizada con un damasquinado de dos hilos, y e foto atamentada de un detalle de la placa hallada en Satucedo (Toledo). Damasquinado en laminas. Fotos cedidas por la Prähistorische Staatssammlung.

Munich.

Debido al hallazgo de una moneda de Wiliza se confirma que la villa de Saucedo estaba en funcionamiento cuando este tipo de cinturon estaba de moda. La presencia de esta placa podria explicarse de varias formas: a) por la existencia de un funcionario militar procedente de (entrocuropa: $h$ ) por la existencia en la Peninsula Iberica de un taller que elaborara este tipo de cinturones. y c) que llegara a la peninsula a traves del comercio con los longobardos, bávaros, alamanos o ávaros.

A pesar de que los análisis tipológicos demuestran que el paralelo más cercano procede de München-Pasing (Baviera) no ocurre lo mismo a través del análisis tecnológico. Este hecho podria confirmar la hipotesis de que la picza procediera de la Italia longobarda donde las placas de Chiusi. del mismo tipo pero evolucionadas, presentan según los análisis realizados por Melucco Vaccaro la misma técnica de producción. Debemos tener en cuenta que la costumbre de enterrar tanto a hombres como a mujeres con ricos ajuares compuestos por armas y objetos de adorno a finales de la época merovingia era caracteristica de algunas regiones centroeuropeas y de la Europa oriental. A finales del siglo vit en Italia longobarda y en Francia se encontraron muy pocas sepulturas con ajuares. En Espana esta ausencia se documenta ya en el siglo vi.

Debido a los pocos hallazgos realizados podriamos dudar de que hubiera llegado a tispaña la moda de los cinturones multiples. Esta hipotesis es poco probable ya que los cinturones multiples son una moda bizantina. Los longobardos y los ávaros tuvieron desde época muy temprana cinturones múltiples realizados con placas de estilo bizantino. Fspaña tenia en el periodo hispano-visigodo una influencia bizantina muy fuerte y es posible que también pudiera emplearse este tipo de cinturón en el armamento. En un enterramiento infantil, sepultura $\mathrm{n}^{\circ} 10 \mathrm{de}$ Daganzo de Arriba (Madrid), se encontró un puñal y una placa colgante de oro con una decoración vegetal. Esta placa de Daganzo parece que debio formar parte de un cinturón múltiple completo. En el mundo funerario visigodo, al parecer, no fue costumbre depositar el atalaje completo de los guerreros, tan sólo se introducirian en las tumbas algunos elementos aislados queriendo simbolizar la posesion del armamento completo.

En Villanueva del Rosario (Málaga) se encontro, in situ, un cinturón múltiple del siglo vi compuesto por treinta placas y una hebilla con 
aguja escutiforme (Luque Moraño, 1979, 165-178, lám.III).

Las decoraciones damasquinadas de estilo semejante a la placa de Saucedo están presentes en la Península Ibérica tal y como se puede apreciar en los frenos de caballo conservados en la Real Armeria de Madrid y en el Instituto Valencia de Don Juan, asi como las dos placas de Solosancho (Avila), todos ellos de procedencia desconocida y dados a conocer por Palol (1957, 298-299, lám. III y IV).

La presencia de una pieza con esta significación social podria darnos una idea de la población situada en la villa de Saucedo. Desconocemos si en este caso su poseedor tendria el mismo status social que aquellos que los poseían en Europa Central. Por lo menos podríamos decir que también aqui sería un objeto característico de los jinetes. La presencia de una basílica con piscina bautismal podría indicarnos la existencia de un asentamiento de un nivel social elevado.

\section{BIBLIOGRAFÍA}

ÅBerG, N., 1923: Die Goten und Langobarden in Italien, Uppsala.

AMENT, H., 1976: «Chronologische Untersuchungen an fränkischen Gräberfeldern der jüngeren Merowingerzeit im Rheinland», Bericht der RömischGermanischen Kommission des Deutschen Archäologischen Instituts, 57, 285-336.

Biegel, G.; Dehn, R., y Fingerlin, G., 1984: Neue Ausgrabungen. Archäologische Denkmalpflege im Regierungsbezirk Freiburg, Freiburg.

BOHNER, K., 1958: «Die fränkischen Altertümer des Trierer Landes», Germanische Denkmäler der Völkerwanderungszeit, B 1, Berlin.

Christlein, R., 1966: «Das alamannische Reihengräberfeld von Marktoberdorf im Allgäu», Materialhefte zur Bayerischen Vorgeschichte, 21, 38-39, Kallmünz.

Christlein, R., 1971: «Das alamannische Gräberfeld von Dirlewang bei Mindelheim», Materialhefte zur Bayerischen Vorgeschichte, 25, Kallmünz.

Christlein, R., 1973: «Besitzabstufungen zur Merowingerzeit im Spiegel reicher Grabfunde aus Westund Süddeutschland», Jahrbuch des Römisch-Germanischen Zentralmuseums Mainz 20, 147-180.

DANNHEIMER, H. 1988: «Aschheim im frühen Mittelalter», Münchner Beiträge zur Vor-und Frühgeschichte 32, I=Veröffentlichungen der Kommission zur archäologischen Erforschung des spätrömischen Raetien der Bayerischen Akademie der Wissenschaften, München.

Fernandez Godin, S., y Pérez de Barradas, J., 1930:
«Excavaciones en la necrópolis visigoda de Daganzo de Arriba (Madrid)", Memorias de la Junta Superior de excavaciones y antigüedades, 114.

FREEDEN, U. V., 1985: "Das Grab eines awarischen Reiters von Moos-Burgstall, Niederbayern», Bericht der Römisch-Germanischen Kommission des Deutschen Archäologischen Instituts, 66, 5-24.

Gorges, J. G., 1979: Les Villes Hispano-Romaines, Paris

GrünewALD, CH., 1988: «Das alamannische Gräberfeld von Unterthürheim, Bayerisch-Schwaben, Materialhefte zur Bayerischen Vorgeschichte», Reihe A-Fundinventare und Ausgrabungsbefunde, 59, Kallmünz.

GuSSMANN, S., 1994: «Herstellungstechnisch-typologistsche Untersuchungen an tauschierten Metallarbeiten. Form und Konstruktionsmerkmale-Tauschierungs-techniken-Reparaturen-Produktion», en: W. Menghuin (ed.) Tauschierarbeiten der Merowingerzeit. Bestandskataloge, 2, 105-158, Berlin.

Hundr, H. J., 1978: « Die Textilreste», en: Paulsen/ Schach-Dörges, 149-163.

1 Longobardi, Cividale del Friuli, 2 giugno-30 sett. 1990, Milano.

JoRGEnSEN, L., 1992: «A. D. 568-A Chronological Analysis of Lombard Graves in Italy", Arkaeologiske Skrifter 5, 94-122=Chronological Studies of Anglo-Saxon England, Lombard Italy and Vendel Period Sweden, Copenhagen.

KellneR, H. J., 1956: «Neue Fundmünzen aus Reihengräbern in Bayern», Bayerische Vorgeschichtsblätter, 21, 122-132.

KNAUT, M., 1993: «Die Alamannischen Gräberfelder von Neresheim und Kösingen, Ostalbkreis"), Forschungen und Berichte zur Vor-und Frühgeschichte in Baden-Württemberg, 48, Stuttgart.

Kосн, U., 1977: Das Reihengräberfeld bei Schretzheim, Germanische Denkmäler der Völkerwanderungszeit A 13, Berlin.

KocH, U., 1982: «Das Fränkische Gräberfeld von Herbolzheim, Kr. Heilbronn», Fundberichte aus Baden-Württemberg, 7, 389-474, Stuttgart.

KoSSACK, 1952: «Zu älteren Reihengräberfunden aus Mindelheim, Schwaben, Bayerische Vorgeschichtsblätter 18/19, 113-116.

LÁszlo, G., 1955: «Etudes Archéologiques sur l'Histoire de la Société des Avares», Archaeologia Hungarica S. N., 34.

LEINFELDER, K., 1951-1952: «Au, Gde. Rehling (Ldkr. Aichach)», Bayerische Vorgeschichtsblätter 18/ $19,1952,290$.

Luque Moraño, A. DE, 1979: «Necrópolis visigoda II de Villanueva del Rosario (Málaga)», Mainake, 1, 165-178.

Melucco Vaccaro, A., 1978: «Il restauro delle deco- 
razioni ageminate «multiple» di Nocera Umbra e di Castel Trosino", Archeologia medievale. Cultura materiale, insediamenti, territorio, 5, 9- 75.

MENGHIN, W., 1994: «Ferrosplendeo opus argento. Der Silberglanz der Merowingerzeit». En: $W$. Menghin (ed.) Tauschierarbeiten der Merowingerzeit. Bestaund Kataloge, 2, Berlin.

Moosbrugger-Leu, R., 1960: « Die frühmittelalterliche Kirche von Tuggen (Kt. Schwyz). Archäologischer Befund", Zeitschrift für Schweizerische Archäologie und Kunstgeschichte, 20, 176-196.

Moosbrugger-Leu, R., 1967: «Die frühmittelalterlichen Gürtelbeschläge der Schweiz», Monographien Zurund Frühgeschichte der Schweiz 14, Basel.

Neuffer-Müller, CH., 1983: «Der alamannische Adelsbestattungsplatz und die Reihengräberfriedhöfe von Kirchheim am Ries (Ostalbkreis)", Forschungen und Berichte Vor-zur Frühgeschichte Baden-Württemberg 15, Stuttgart.

PALOL, P. DE, 1957: «Bronces con decoración damasquinada en época visigoda», $V$ Congreso de Arqueologia Nacional, Zaragoza, 292-305.

PAULSEN, P., 1967: «Alamannische Adelsgräber von Niederstotzingen (Kreis Heidenheim)", Veröffentlichungen des Staatlichen Amtes für Denkmalpflege Stuttgart A 12, Stuttgart.

Paulsen, P., y Schach-DORges, H., 1978: «Das alamannische Gräberfeld von Giengen an der Brenz (Kreis Heidenheim)", Forschungen und Berichte zur Vorund Frühgeschichte in Baden-Württemberg, Stuttgart.

Posac Mon, C. F., 1952: «Solosancho (Avila)», Noticiario Arqueológico Hispánico, 63-74.

Ramos SAINZ, Ma. L., 1992: «Una piscina bautismal de planta cruciforme descubierta en la villa romana de Saucedo (Talavera de la Reina, Toledo)", III Reunió d'Arqueologia cristiana Hispánica, 105-110, Barcelona (Maó, 1988).

Ramos Sainz, M. ${ }^{a}$ L., y Castelo Ruano, R., 1992: «Excavaciones en la villa romana de Saucedo (Talavera de la Reina, Toledo). Ultimos avances en relación al hallazgo de una basílica paleocristiana", Actas de las primeras Jornadas de Arqueología de Talavera la Reina y sus tierras, 115137, Talavera de la Reina.

Ramos Sainz, Ma . L., y Durán Cabello, R., 1988: «La villa romana de Saucedo (Talavera de la Reina, Toledo), aportaciones a un estudio en relación a la implantación de villas en la Vega del Tajo", I Congreso de Historia de Castilla-La Mancha, 237-243, Toledo (Ciudad Real, 1985).

REINECKE, 1925: «Reihengräber und Friedhöfe der Kirchen", Germania, 9, 103-107.

SAlin, M. E., 1957: La civilisation mérovingienne 3, 163-166.
SALIN, M. E., 1951: «Les techniques de la damasquinure en Gaule Mérovingienne», Gallia. Fouilles et Monuments archéologiques en France métropolitaine, 9, 31-52.

Salin, M. E., y France-Lanord, A., 1943: Le fer à l'époque mérovingienne, Paris.

SASSE, B., 1982: «Die Sozialstruktur Böhmens in der Frühzeit», Historisch-archäologische Untersuchungen zum 9-12. Jahrhundert, Germania Slavica $4=$ Berliner Historische Studien 7, Berlin.

SASSE, B., 1989: «Leben am Kaiserstuhl im Frühmittelalter. Ergebnisse einer Ausgrabung bei Eichstetten", Archäologische Informationen aus Baden-Württemberg 10, Stuttgart.

SASSE, B., (en prensa): «Ein frühmittelalterliches Reihengräberfeld bei Eichstetten am Kaiserstuhl». Forschungen und Berichte zur Vor-und Frühgeschichte in Baden-Württemberg, Stuttgart.

STEIN, F., 1967: «Adelsgräber des achten Jahrhunderts in Deutschland», Germanische Denkmäler der Völkerwanderungszeit A 9, Berlin.

Steuer, H., 1968: «Zur Bewaffnung und Sozialstruktur der Merowingerzeit», Nachrichten aus Niedersachsens Urgeschichte 37, 18-87.

Steuer, H., 1977: «Bemerkungen zur Chronologie der Merowingerzeit», Studien zur Sachsenforschung, 1, 375-402, Hildesheim.

STEUER, H., 1982: «Frühgeschichtliche Sozialstrukturen in Mitteleuropa, Abhandlungen der Akademie der Wissenschaften zu Göttingen», Phil.Hist. Kl. 3, 128, Göttingen.

Steuer, H., y LAST, M., 1969: «Zur Interpretation der beigabenführenden Gräber des 8 . Jahrhunderts im Gebiet rechts des Rheins", Nachrichten aus Niedersachsens Urgeschichte 38, 25-88.

WERNER, J., 1935: «Münzdatierte Austrasische Grabfunde», Germanische Denkmäler der Völkerwanderungszeit 3, Berlin-Leipzig.

WERNER, J., 1953: «Das alamannische Gräberfeld von Bülach», Monographien zur Ur-und Frühgeschichte der Schweiz 9, Basel.

WERNER, J., 1955: «Das alamannische Gräberfeld von Mindelheim", Materialhefte zur Bayerischen Vorgeschichte, 6, Kallmünz.

WERNER, J., 1968: «Bewaffung und Waffenbeigabe in der Merowingerzeit», Settimane di Studio del centro italiano di Studi sull' alto Medioevo, 15, 195 y ss.

WERNER, J., 1974: «Nomadische Gürtel bei Persern, Byzantinern und Langobarden", Accad. Naz, dei Lincei, 371, Roma $=$ La Civiltà dei Longobardi in Europa .

ZEISs, H., 1934: Die Grabfunde aus dem spanischen Westgotenreich, Berlin-Leipzig.

Zeiss, H., 1935: «Der Schatzfund von Akalan», Forschungen und Fortschritte, 11, 17-18. 